\title{
Analysis of evaporation and thermal decomposition of ionic liquids by thermogravimetrical analysis at ambient pressure and high vacuum $\uparrow$
}

\author{
Florian Heym, ${ }^{a}$ Bastian J. M. Etzold, ${ }^{b}$ Christoph Kern ${ }^{a}$ and Andreas Jess ${ }^{a}$ \\ Received 3rd December 2010, Accepted 7th April 2011 \\ DOI: $10.1039 / \mathrm{cogc00876a}$
}

Ionic liquids (ILs) are widely discussed as alternative green solvents not only because of their unique chemical properties, but also because of their extremely low vapour pressure and - at least in some cases - relatively high thermal stability. Two complementary methods are analyzed and compared to determine both the rate constant of decomposition and the vapour pressure of four ILs: (1) thermogravimetrical analysis at ambient pressure $\left(\mathrm{TG}_{\mathrm{ap}}\right)$ with an overflow of inert gases, and (2) high vacuum (HV) experiments with a magnetic suspension balance (MSB). At ambient pressure, $[\mathrm{EMIM}]\left[\mathrm{MeSO}_{3}\right]$ and $[\mathrm{EMIM}]\left[\mathrm{CF}_{3} \mathrm{SO}_{3}\right]$ decompose without a significant contribution of evaporation, which leads to the rate constant of thermal degradation. For both ILs, the vapour pressure can only be determined at HV by the MSB, because the evaporation rate is then higher than the decomposition rate. For the relatively volatile ILs [EMIM] $\left.\mathrm{NTf}_{2}\right]$ and $[\mathrm{BMIM}]\left[\mathrm{NTf}_{2}\right]$ the vapour pressure can be derived both by the MSB at $\mathrm{HV}$ as well as by $\mathrm{TG}_{\mathrm{ap}}$. General strategies to determine the volatility and stability of ILs and criteria for the maximum operation temperature with regard to decomposition and evaporation are presented.

\section{Introduction}

Ionic liquids (ILs) are widely discussed as alternative green solvents, e.g. for separation processes or homogeneous catalysis. Besides their unique chemically "tunable" properties, ILs have the advantage of an extremely low vapour pressure and at least some ILs have a relatively high thermal stability. Both parameters are important for the use of ILs in research and technical applications, and the maximum allowable operation temperature to exclude relevant mass losses by evaporation or decomposition should be well-known.

Although ILs have - like any other liquid - a vapour pressure (although extraordinary low), statements like "ILs have no effective vapour pressure", a "non-volatile character" and "no measurable vapour pressure" were and are still found in the literature, e.g. ref. 1-3. In 2005/2006, the debate about the vapour pressure of ILs changed, when Rebelo et al. ${ }^{4}$ and Earle et al. ${ }^{5}$ showed that $\left[\mathrm{NTf}_{2}\right]$-based ILs like [EMIM][NTf $\left.{ }_{2}\right]$,

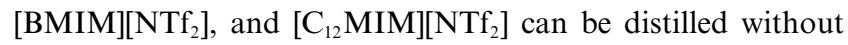
decomposition at a low pressure of 10 to $1000 \mathrm{~Pa}$ and temperatures around $300^{\circ} \mathrm{C}$. Probably the first quantitative analysis of

\footnotetext{
${ }^{a}$ Chair of Chemical Engineering, University Bayreuth, D-95440,

Bayreuth, Germany.E-mail:Jess@uni-bayreuth.de

${ }^{b}$ Chair of Chemical Reaction Engineering, University

Erlangen-Nuremberg, D-91058, Erlangen, Germany

$\dagger$ This paper was published as part of the themed issue of contributions from the Green Solvents - Alternative Fluids in Science and Application conference held in Berchtesgaden, October 2010.
}

the vapour pressure of an IL was conducted by Paulechka $\mathrm{et} \mathrm{al.}{ }^{6}$ in 2005 for [BMIM] $\left[\mathrm{NTf}_{2}\right]$, showing that the vapour pressure is about $0.1 \mathrm{~Pa}$ for $215^{\circ} \mathrm{C}$. To the best of our knowledge, Paulechka et al. ${ }^{7}$ in 2003 were also the first to predict the vapour pressure of an IL ([BMIM] $\left.\mathrm{PF}_{6}\right]$ ) based on thermodynamic properties (cohesive energy density, heat capacities), estimating $10^{-10} \mathrm{~Pa}$ for $25^{\circ} \mathrm{C}$.

Until today, the vapour pressure data is still very limited, mainly because the determination is so onerous. In addition, decomposition may take place at temperatures at which the vapour pressure becomes measurable with usual techniques, and the discrimination, whether evaporation is superimposed by degradation, is then not easy. It is also still a matter of debate over which methods should be used to determine the vapour pressure as well as the kinetic parameters of thermal degradation of ILs, and what reasonable conclusions can be drawn from these results, for example to define a maximum operation temperature.

Usually, the thermal stability of ILs is characterized by thermogravimetrical analysis (TGA) at ambient pressure in overflow of an inert gas with a constant heating rate, typically 1 to $20 \mathrm{~K} \mathrm{~min}^{-1}{ }^{8,9,10}$ The so-called onset temperature $\left(T_{\text {onset }}\right)$, at which a certain detectable mass loss of, for example, $1 \%$ is reached, is then used as a synonym for the decomposition temperature to define the stability of ILs. ${ }^{8,11}$ The application of $T_{\text {onset }}$ may be useful as a comparative value, but not as a quantitative measure of the stability as already discussed in a previous publication: ${ }^{12}$ 
$\circ T_{\text {onset }}$ depends on a variety of parameters such as the heating and volume rate or the crucible's geometry, and is therefore not at all a material property, which makes the comparison of literature data problematic. ${ }^{12,13}$

$\circ T_{\text {onset }}$ leads in most cases to an overestimation of the operation limit. ${ }^{14-16}$ The duration of a TG experiment is usually less than one day, but the IL may already decompose substantially at a lower temperature if treated for a period of let's say several months.

- For applications of ILs, even a mass loss of $1 \%$ per year may be critical. Instead of time-consuming isothermal experiments (or the use of the vague value of $T_{\text {onset }}$ ), the critical operation temperature can be estimated by extrapolation of data measured at $T>T_{\text {crit }}$, if the decomposition kinetics are well-known, for example by an Arrhenius approach. ${ }^{12,16,17}$

- The overall mass loss of an IL may be the result of evaporation and/or thermal decomposition, as shown for [BMIM] $\left[\mathrm{NTf}_{2}\right]_{.}{ }^{12}$ Decomposition limits in any case $T_{\text {crit }}$, but at least in open systems in contact to a gas phase, evaporation also has to be considered.

In order to overcome these problems related to $T_{\text {onset }}$, simple but also accurate methods to determine the parameters of decomposition and evaporation would be helpful. As shown in previous publications, ${ }^{12}$ thermogravimetrical non-isothermal analysis (TGA) at ambient pressure with different carrier gases such as $\mathrm{He}$ and $\mathrm{N}_{2}$ is a suitable method to discriminate between evaporation and decomposition. For decomposition only, the mass loss does not depend on the gas, as shown for $[\mathrm{EMIM}]\left[\mathrm{EtSO}_{4}\right]^{12}$ Based on the simulation of the TG experiment, the kinetic parameters of decomposition can be deduced and then used to estimate the maximum long term operation temperature of ILs, e.g. by the criterion of $1 \%$ mass loss per year. ${ }^{12,13}$ If evaporation takes place, the mass loss is faster with $\mathrm{He}$ than with $\mathrm{N}_{2}$ as carrier gas, and evaporation has to be considered. If evaporation and decomposition occur simultaneously, the simulation of the TG experiments leads to the individual rates of both processes, as shown for [BMIM][ $\left.\mathrm{NTf}_{2}\right]^{12}$

In case the IL only decomposes at ambient pressure without a measurable contribution of evaporation, the vapour pressure has to be measured by complementary measurements at very low pressures, typically $<0.1 \mathrm{~Pa}$ in the case of ILs, see section 4.2. The evaporation rate is then determined by the free flight of the vapour molecules (IL ion pairs) from the surface of the liquid sample into the vacuum chamber. This effusion process is orders of magnitude faster than ordinary molecular diffusion at ambient pressure, and may determine the overall mass loss, as the rate of thermal degradation does not depend on pressure.

In this work, these two complimentary methods to determine the parameters of decomposition and evaporation are analysed: (1) non-isothermal TGA at ambient pressure with a cylindrical crucible in overflow of $\mathrm{He}$ or $\mathrm{N}_{2}$, and (2) isothermal high vacuum (HV) experiments with a magnetic suspension balance (MSB). The ambient pressure TG-measurements were partly presented and analyzed in previous publications. ${ }^{12,13}$ Thus, the HV experiments with the MSB and the comparison of both methods are here in the focus and discussed in detail.

The present paper is also an attempt to bring more insight into the debatable term "technically relevant mass loss" and to give two clear guidelines for users of ILs: (1) how the vapour pressure and the kinetics of thermal decomposition should be determined, and (2) how to arrive at conclusions for the maximum operation temperature of ILs.

Four ILs were chosen. [EMIM] $\left[\mathrm{MeSO}_{3}\right]$ and [EMIM]$\left[\mathrm{CF}_{3} \mathrm{SO}_{3}\right]$ decompose at ambient pressure without a measurable contribution of evaporation, and the vapour pressure can only be determined at $\mathrm{HV}$. To the contrary, [EMIM][NTf $\mathrm{NT}_{2}$ and $[\mathrm{BMIM}]\left[\mathrm{NTf}_{2}\right]$ are relatively volatile ILs, i.e. depending on the conditions (e.g. heating rate) evaporation and/or decomposition may determine the mass loss even at ambient pressure. , $12,13,18,19$

\section{Experimental}

[EMIM] $\left[\mathrm{NTf}_{2}\right]$ and [BMIM] $\left[\mathrm{NTf}_{2}\right]$ were purchased from Iolitec (purity 99\%), [EMIM] $\left[\mathrm{MeSO}_{3}\right]$ and [EMIM] $\left[\mathrm{CF}_{3} \mathrm{SO}_{3}\right]$ from BASF (98\%). All ILs were dried and purified during the initial phase of the thermogravimetrical analysis. TGA at ambient pressure was conducted in an EXSTAR 6300 (Seiko Instr.) with $\mathrm{N}_{2}\left(99.999 \%\right.$ purity) or $\mathrm{He}(99.996 \%)\left(61 \mathrm{~h}^{-1} \mathrm{NTP}\right)$ at heating rates between 0.1 and $10 \mathrm{~K} \mathrm{~min}^{-1}$. The flow rates of $\mathrm{He}$ and $\mathrm{N}_{2}$ were always high enough to insure that the partial pressure of the IL vapour in the bulk phase is negligibly small. The HV experiments $\left(10^{-5} \mathrm{~Pa}\right)$ were conducted with a magnetic suspension balance (Fig. 1); selected experiments were done at higher pressures of up to 1 bar. In the following, the abbreviation $\mathrm{TG}_{\mathrm{ap}}$ (ap: ambient pressure) is used for the TGA in overflow of a gas, $\mathrm{MSB}_{\mathrm{ap}}$ for experiments with the magnetic suspension balance with a stagnant gas phase, and $\mathrm{MSB}_{\mathrm{HV}}$ for magnetic suspension balance measurements in high vacuum.

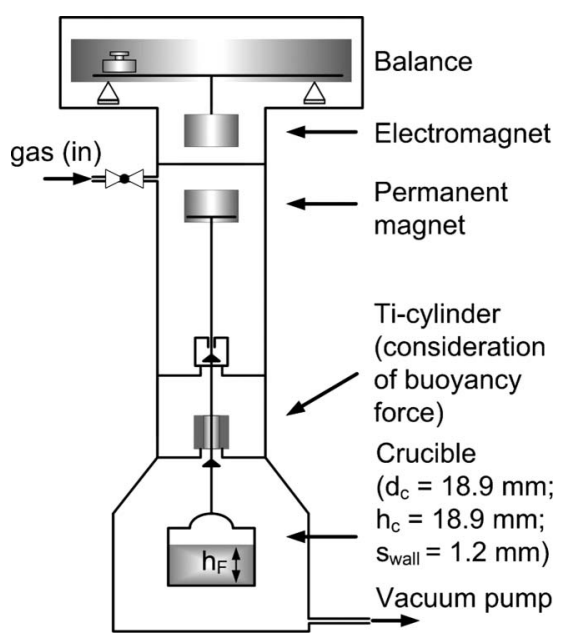

Fig. 1 Setup of the isothermal HV experiments with a magnetic suspension balance (Rubotherm). For details on the non-isothermal ambient pressure thermogravimetrical analysis with a crucible in overflow of a gas $\left(\mathrm{N}_{2}\right.$ or $\left.\mathrm{He}\right)$, see a previous publication. ${ }^{12}$

\section{Data evaluation and modelling methodology}

\subsection{Evaporation and decomposition at ambient pressure (TG measurements)}

For ambient pressure TG measurements in overflow of a carrier gas, the rate of evaporation is equivalent to the rate of mass transfer from the gas/liquid interphase to the bulk phase of 
the gas flowing over the crucible. For the assumption that the partial pressure at the interface equals the vapour pressure $\left(p_{\text {vap }}\right)$ and that the partial pressure in the bulk phase of the carrier gas is negligible small the rate of mass loss by evaporation of component $\mathrm{i}$ is given by:

$$
-\left.\frac{\mathrm{d} m_{i}}{\mathrm{~d} t}\right|_{\text {evaporation }}=M_{i} \beta_{\mathrm{C}} A_{\mathrm{C}} \frac{p_{\text {vap }, i}}{R T}, \quad \text { with } \beta_{\mathrm{C}}=\frac{S h_{\mathrm{d}} D_{i, \mathrm{~g}}}{d_{\mathrm{C}}}
$$

The mass transfer coefficient $\beta_{\mathrm{C}}$ has to consider both the internal diffusion in the crucible and the subsequent external transport into the gas flowing over the crucible's upper end plane. In this work, a correlation for $\beta_{\mathrm{C}}$ and the corresponding Sherwood number $S h_{\mathrm{d}}$, respectively, was used, which is valid for any gas species, gas velocity, and geometry and filling height of cylindrical crucibles, and which was derived in a previous work by numerical methods. ${ }^{12}$ The binary diffusion coefficient $D_{i, \mathrm{~g}}$ of the vapour of the IL (assumed to consist of ionic pairs) in the gas was calculated by the correlation of Fuller, Schettler and Giddings. ${ }^{20}$ (Values of $D_{i, \mathrm{~g}}$ listed in Table 1; for details see previous publication. ${ }^{12}$ )

The vapour pressure is calculated by a simplified Antoine equation based on the entropy term $C_{\mathrm{vap}, i}$ and the enthalpy of vaporisation $\Delta_{\text {vap }} H_{i}$, both assumed to be temperature-independent:

$$
\frac{p_{\text {vap }, i}}{p_{\text {ref }}}=C_{\text {vap }, i} e^{-\frac{\Delta_{\mathrm{vap}} H_{i}}{R T}}, \quad \text { with } p_{\text {ref }}=1 \mathrm{~Pa}
$$

For the assumption of a first order reaction, the rate of thermal decomposition is given by

$$
-\left.\frac{\mathrm{d} m_{i}}{\mathrm{~d} t}\right|_{\text {decomposition }}=k_{\text {decomposition }, i} m_{i}, \quad \text { with } k_{\text {decomposition }, i}=k_{0, i} e^{-\frac{E_{\mathrm{A}, i}}{R T}}
$$

Instead of the residual mass $m_{i}$, the degree of evaporation/conversion by decomposition $\left(X_{i}\right)$ can be used $\left(X_{i}=1-\right.$ $m_{i} / m_{i, 0}$ with $m_{i, 0}$ as initial mass), and eqn (1) to (3) yield the total rate of mass loss, if decomposition and evaporation take place simultaneously:

$-\left.\frac{1}{m_{0, i}} \frac{\mathrm{d} m_{i}}{\mathrm{~d} t}\right|_{\text {total }}=\left.\frac{\mathrm{d} X_{i}}{\mathrm{~d} t}\right|_{\text {total }}=\left(\frac{M_{i} A_{\mathrm{C}}}{R T m_{0, i}}\right) \beta_{\mathrm{C}} p_{\text {vap }, i}+k_{\text {decomposition }, i}\left(1-X_{i}\right)$

For decomposition or evaporation only, eqn (4) simplifies, and either the first or second term on the right side of eqn (4) is negligible. For the non-isothermal TG experiments, the heating rate HR was kept constant, i.e. $T=T_{0}+\mathrm{HR} t$ and $\mathrm{d} t=\mathrm{d} T / \mathrm{HR}$, respectively.

If only decomposition takes place, the rate of mass loss does not depend on the carrier gas that is used. Vice versa, if only evaporation occurs, experiments with different gases (here $\mathrm{N}_{2}$ and $\mathrm{He}$ ) and thus of different mass transfer coefficients $\beta_{\mathrm{C}}$ (via different values of $D_{i, \mathrm{~g}}$ ) will lead to a clear difference in the rates of mass loss. Thus, the variation of the gas is the method of choice to distinguish between both cases (details in a previous publication $^{12}$ ).

\subsection{Evaporation of ionic liquids at high vacuum (HV)}

For HV, intermolecular collisions are negligible, and the mass loss by evaporation (effusion) is only determined by the free flight of the vapour molecules from the surface of the liquid into the vacuum chamber (see textbooks of physical chemistry, e.g. $\left.{ }^{21}\right)$. The mean velocity of gas molecules, $u_{\text {mol }}$, is

$$
u_{\mathrm{mol}}=\sqrt{\frac{8 R T}{\pi M}}
$$

According to the kinetic theory of gases the term $\frac{1}{4} u_{\text {mol }} c_{\text {vap }}$ represents the number of collisions of gas molecules per unit area with a "wall" for a given gas (vapour) concentration $c_{\text {vap }}$. For the cylindrical crucible of the MSB with surface area (upper plane) $\mathrm{A}_{\mathrm{C}}$, the molar rate of mass loss of the IL $\mathrm{i}$ with molar mass $M_{i}$ (ion pair) by effusion at $\mathrm{HV}$ is then given by

$$
-\frac{\mathrm{d} n_{i}}{\mathrm{~d} t}=\frac{1}{4} u_{\mathrm{mol}} c_{\mathrm{vap}, i} A_{\mathrm{C}}
$$

The ideal gas law and the insertion of eqn (5) into eqn (6) yield the rate of mass loss:

$$
\begin{aligned}
-\frac{\mathrm{d} m_{i}}{\mathrm{~d} t} & =-\frac{\mathrm{d} n_{i}}{\mathrm{~d} t} M_{i} \\
& =\frac{1}{4} \sqrt{\frac{8 R T}{\pi M_{i}}} \frac{p_{\text {vap }, i}}{R T} A_{\mathrm{C}} M_{i} \\
& =\sqrt{\frac{M_{i} R T}{2 \pi}} A_{\mathrm{C}} \frac{p_{\text {vap }, i}}{R T} \quad\left(\text { for } p_{\text {total }} \rightarrow 0\right)
\end{aligned}
$$

This rate of mass loss is orders of magnitude higher than by ordinary diffusion at ambient pressure, and so $p_{\text {vap }}$ is simply derived by eqn (7) based on HV measurements at low temperatures, where the contribution of thermal decomposition is most probably negligible. . $^{12,18,22}$

If the pressure in the MSB used for the HV experiments is increased, the effective rate of mass loss is given by a combination of ordinary diffusion and the free flight of the molecules:

$$
\begin{aligned}
& -\left.\frac{\mathrm{d} m_{i}}{\mathrm{~d} t}\right|_{\text {evaporation }}=\left(\frac{1}{M_{i} \beta_{\mathrm{C}}}+\frac{1}{\sqrt{\frac{M_{i} R T}{2 \pi}}}\right)^{-1} A_{\mathrm{C}} \frac{p_{\text {vap }}}{R T} \\
& \text { (for } 10^{-5} \mathrm{~Pa}<p_{\text {total }}<10^{5} \mathrm{~Pa} \text { ) }
\end{aligned}
$$

For a very low pressure (high value of $\beta_{\mathrm{C}}$ ), eqn (8) leads to the border case of eqn (7), and for a high pressure, eqn (8) yields eqn (1).

\section{Results and discussion}

\subsection{Non-isothermal TGA of ILs at ambient pressure with an overflow of an inert gas}

Results of non-isothermal TG-experiments with [EMIM]$\left[\mathrm{EtSO}_{4}\right]$ and $[\mathrm{BMIM}]\left[\mathrm{NTf}_{2}\right]$ were already presented previously. ${ }^{12,13}$ Thus here, only selected new results with the ILs [EMIM] $\left[\mathrm{NTf}_{2}\right]$ and $[\mathrm{EMIM}]\left[\mathrm{MeSO}_{3}\right]$ are presented. 
Table 1 Material properties of the investigated ionic liquids

Diffusion coefficient in $10^{-5} \mathrm{~m}^{2} \mathrm{~s}^{-1}(293 \mathrm{~K}, 1$ bar)

\begin{tabular}{|c|c|c|c|c|}
\hline Ionic liquid & in $\mathrm{N}_{2}$ & in $\mathrm{He}$ & Molar mass in $\mathrm{g} \mathrm{mol}^{-1}$ & Density in $\mathrm{g} \mathrm{cm}^{-3}(298 \mathrm{~K})$ \\
\hline$[\mathrm{EMIM}]\left[\mathrm{NTf}_{2}\right]$ & 0.70 & 1.7 & 391 & 1.52 \\
\hline [BMIM][NTf $\left.{ }_{2}\right]$ & 0.65 & 1.6 & 419 & 1.44 \\
\hline$[\mathrm{EMIM}]\left[\mathrm{MeSO}_{3}\right]$ & 0.88 & 2.2 & 206 & 1.24 \\
\hline$[\mathrm{EMIM}]\left[\mathrm{CF}_{3} \mathrm{SO}_{3}\right]$ & 0.82 & 2.1 & 260 & 1.38 \\
\hline
\end{tabular}

[EMIM] $\left[\mathrm{NTf}_{2}\right]$ is being known for a certain vapour pressure and a high thermal stability. ${ }^{5,12,13,19}$ Fig. 2 shows that the rate of mass loss at ambient pressure is much higher in He compared to $\mathrm{N}_{2}$, indicating that evaporation dominates at the given low heating rate of $0.1 \mathrm{~K} \mathrm{~min}^{-1}$. This is confirmed by the goodness of the fit both for $\mathrm{N}_{2}$ and He. For the calculation, eqn (1) - in combination with eqn (2) - was solved numerically (software Berkeley Madonna) with $C_{\text {vap }}$ and $\Delta_{\text {vap }} H$ as fitting parameters. For comparison, the very small contribution of thermal decomposition is also shown, which was calculated by eqn (3) (parameters see Table 2) based on experiments with a much higher heating rate of $10 \mathrm{~K} \mathrm{~min}^{-1} \cdot{ }^{12,24}$

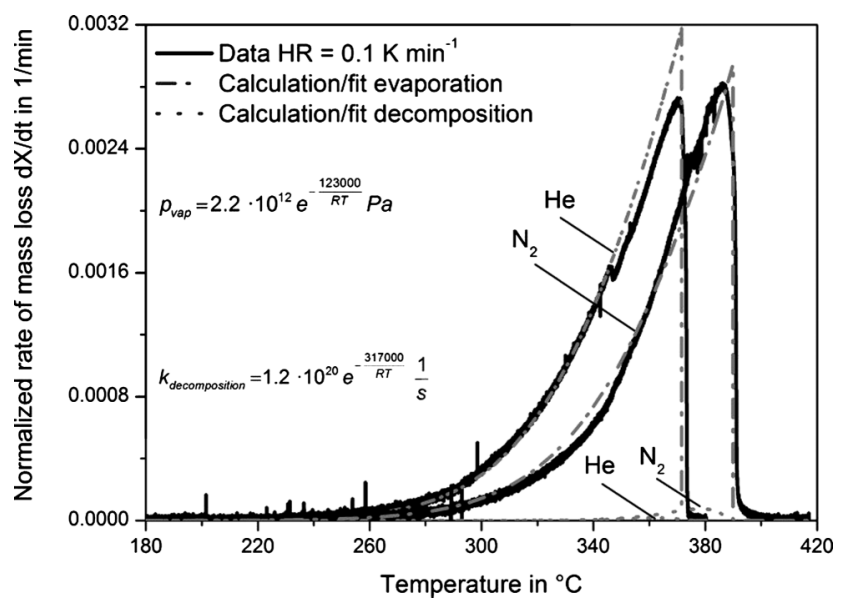

Fig. 2 TG/DTG experiment with [EMIM] $\left[\mathrm{NTf}_{2}\right]$ in $\mathrm{N}_{2}$ and $\mathrm{He}$ and comparison with simulation (eqn (1) and (2)), if only evaporation or only decomposition of the (residual) measured mass is considered $(0.1 \mathrm{~K}$ $\min ^{-1}, 61 \mathrm{~h}^{-1}$ (NTP), $1 \mathrm{bar}, h_{\mathrm{F}, 0}=1.83 \mathrm{~mm}$ (initial filling degree of $80 \%$ ) for $\mathrm{N}_{2}$ and $1.92 \mathrm{~mm}(83 \%)$ for $\left.\mathrm{He}\right)$. The very small contribution of decomposition was calculated eqn (3) and the kinetic data as given in Table 2.
Fig. 2 indicates that decomposition temperatures reported as the start or onset of the TG analysis should be handled with caution. For example, Crosthwaite et al. reported that the starting temperature is $347^{\circ} \mathrm{C}$ for $\left[\mathrm{C}_{8} \mathrm{MIM}\right]\left[\mathrm{NTf}_{2}\right](\mathrm{HR}=$ $\left.0.2 \mathrm{~K} \mathrm{~min}^{-1}, \mathrm{~N}_{2}\right) .{ }^{23}$ [EMIM] $\left[\mathrm{NTf}_{2}\right]$ and [BMIM] $\left[\mathrm{NTf}_{2}\right]$, which were investigated in the present work, have a similar structure as $\left[\mathrm{C}_{8} \mathrm{MIM}\right]\left[\mathrm{NTf}_{2}\right]$. Thus, most probably, $\left[\mathrm{C}_{8} \mathrm{MIM}\right]\left[\mathrm{NTf}_{2}\right]$ also evaporates at low heating rates and the starting temperature given by Crosthwaite reflects evaporation and not decomposition.

If the TGA is done with a much higher heating rate (e.g. $10 \mathrm{~K} \mathrm{~min}^{-1}$ ), the regime relevant for the mass loss is shifted to higher temperatures. Now, the influence of the gas $\left(\mathrm{N}_{2}\right.$ or $\mathrm{He}$ ) is less pronounced and decomposition gets more and more important, as the activation energy (here $317 \mathrm{~kJ} \mathrm{~mol}^{-1}$ ) is higher than the enthalpy of evaporation $\left(120 \mathrm{~kJ} \mathrm{~mol}^{-1}\right)$. A simulation of the measured DTG signal at a high heating rate of $10 \mathrm{~K}$ $\mathrm{min}^{-1}$ is possible, if both the evaporation and the decomposition are considered, and the combination of evaporation (with the already known parameters $C_{\text {vap }}$ and $\Delta_{\text {vap }} H$ ) and of thermal decomposition leads to the overall rate of mass loss. The best fit of the simulations and the experiments in $\mathrm{He}$ and $\mathrm{N}_{2}$ finally yields the rate constant of thermal decomposition and the respective parameters $k_{0}$ and $E_{\mathrm{A}}$; further details on this case and method for a similar IL ([BMIM] $\left.\left[\mathrm{NTf}_{2}\right]\right)$ are found elsewhere. ${ }^{12,24}$

Compared to both $\left[\mathrm{NTf}_{2}\right]$-based ILs, [EMIM] $\left[\mathrm{MeSO}_{3}\right]$ and also [EMIM] $\left[\mathrm{CF}_{3} \mathrm{SO}_{3}\right]$ show a different behaviour, and practically only decomposition takes place at ambient pressure. This is shown for [EMIM] $\left[\mathrm{MeSO}_{3}\right]$ in Fig. 3. The mass loss does not depend on the carrier gas, which clearly indicates that [EMIM] $\left[\mathrm{MeSO}_{3}\right]$ only decomposes without a contribution of evaporation. The parameters of the rate constant of decomposition $\left(k_{0}, E_{\mathrm{A}}\right)$ were determined by eqn (3) and a respective fit. The dashed black lines in Fig. 3 represent the negligible contribution

Table 2 Parameters of decomposition (eqn (4)) as determined by TGA at ambient pressure in overflow of an inert gas (TG $\mathrm{Tap}_{\text {ap }}$ and by a magnetic suspension balance at 1 bar $\left(\right.$ MSB $\left._{\text {ap }}\right)$

\begin{tabular}{|c|c|c|c|c|c|c|c|}
\hline \multirow[b]{2}{*}{ Ionic liquid } & \multicolumn{2}{|l|}{$\mathrm{TG}_{\mathrm{ap}}$} & \multicolumn{2}{|l|}{$\mathrm{MSB}_{\mathrm{ap}}$} & \multicolumn{3}{|c|}{ Recommended values $^{a}$} \\
\hline & $k_{0}$ in $\mathrm{s}^{-1}$ & $E_{\mathrm{A}}$ in $\mathrm{kJ} \mathrm{mol}^{-1}$ & $k_{0}$ in $\mathrm{s}^{-1}$ & $E_{\mathrm{A}}$ in $\mathrm{kJ} \mathrm{mol}^{-1}$ & $k_{0}$ in $\mathrm{s}^{-1}$ & $E_{\mathrm{A}}$ in $\mathrm{kJ} \mathrm{mol}^{-1}$ & $k_{\text {decomposition }}$ at $500 \mathrm{~K}_{\text {in s }}{ }^{-1}$ \\
\hline$[\mathrm{EMIM}]\left[\mathrm{NTf}_{2}\right]$ & $1.2 \times 10^{20}$ & 317 & not measurable & not measurable & $1.2 \times 10^{20}$ & 317 & $9.4 \times 10^{-14}$ \\
\hline$[\mathrm{BMIM}]\left[\mathrm{NTf}_{2}\right]^{b}$ & $1.2 \times 10^{18}$ & 287 & not measurable & not measurable & $1.2 \times 10^{18}$ & 287 & $1.3 \times 10^{-12}$ \\
\hline$[\mathrm{EMIM}]\left[\mathrm{MeSO}_{3}\right]$ & $3.9 \times 10^{13}$ & 189 & $4.4 \times 10^{8}$ & 142 & $2.9 \times 10^{14}$ & 199 & $4.7 \times 10^{-7}$ \\
\hline$[\mathrm{EMIM}]\left[\mathrm{CF}_{3} \mathrm{SO}_{3}\right]$ & $3.2 \times 10^{11}$ & 184 & not measured $^{c}$ & & $3.2 \times 10^{11}$ & 184 & $1.9 \times 10^{-8}$ \\
\hline
\end{tabular}

${ }^{a}$ For $[\mathrm{EMIM}]\left[\mathrm{MeSO}_{3}\right]$ data of decomposition were determined by both experimental methods; ${ }^{24}$ then all data were used for the fitting (Fig. 6). For the other ILs data of $\mathrm{TG}_{\mathrm{ap}}$ were used. The maximum temperature of the MSB is limited to $300{ }^{\circ} \mathrm{C}$, which is too low to detect decomposition of

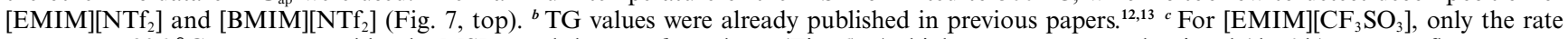
constant at $206{ }^{\circ} \mathrm{C}$ was measured by the $\mathrm{MSB}_{\mathrm{ap}}$ and thus not $k_{0}$ and $E_{\mathrm{A}}$. (Fig. 6). At higher temperatures, the signal (dm/d $\left.t\right)$ starts to fluctuate too strong. The reason is not yet clear, but probably free convection in the stagnant gas phase of the MSB disturbed the measurements. 


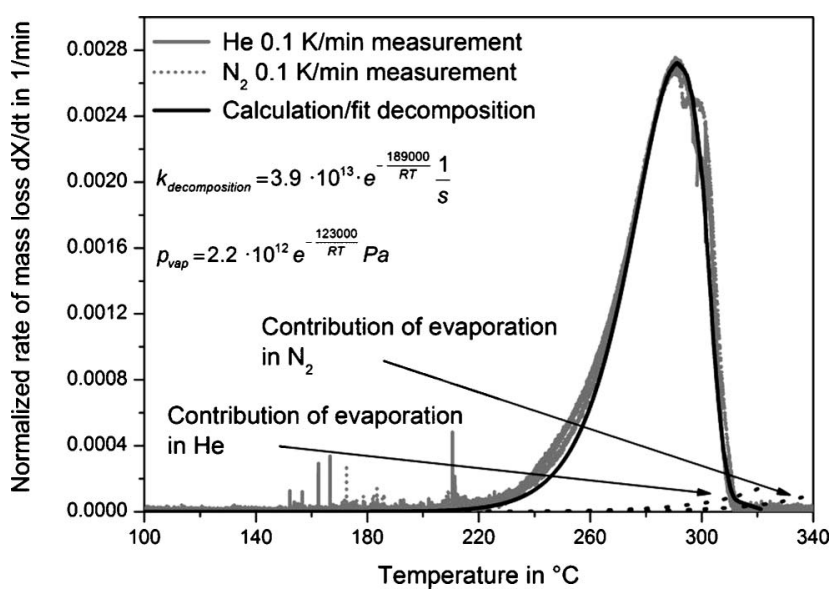

Fig. 3 TG/DTG experiment at 1 bar with [EMIM] $\left[\mathrm{MeSO}_{3}\right](\mathrm{HR}=$ $\left.0.1 \mathrm{~K} \mathrm{~min}^{-1}\right)$ with $\mathrm{N}_{2}$ and $\mathrm{He}\left(\mathrm{N}_{2}\right.$ : initial filling level $\left(h_{\mathrm{F}, 0}\right)$ of $1.56 \mathrm{~mm}$, He: $h_{\mathrm{F}, 0}=1.6 \mathrm{~mm}$ ). The very small contribution of evaporation in $\mathrm{N}_{2}$ and $\mathrm{He}$ was calculated by the vapour pressure determined by the MSB at HV (section 4.2). For the simulation of the contribution of evaporation, the (residual) measured mass was considered.

of evaporation (in $\mathrm{He}$ and $\mathrm{N}_{2}$ ), which were calculated by the eqn (1) and (2) and the vapour pressure determined at HV (see section 4.2). The rate of evaporation is more than one order of magnitude lower than the rate of decomposition (Fig. 3). Hence, for conditions relevant for practical applications (ambient or higher pressure), decomposition of [EMIM] $\left[\mathrm{MeSO}_{3}\right]$ always dominates, vaporisation is negligible, and the vapour pressure cannot be determined by ambient pressure TGA. In Table 2, the kinetic parameters are summarized.

The reliability of the kinetic data of decomposition was also checked by an isothermal long-term test of 5 weeks with [EMIM] $\left[\mathrm{MeSO}_{3}\right]$ as example. A flask with $40 \mathrm{~g}$ was kept in contact with air at $215 \pm 3{ }^{\circ} \mathrm{C}$. The following mass losses were measured: $3 \%$ (after $31 \mathrm{~h}$ ), 17\% (10 days). 38\% (20 d), and $82 \%$ (37 d) compared to the calculated values of $3 \%, 18 \%, 33 \%$ and $52 \%$. Thus for a mass loss of up to $40 \%$, the agreement of measurement and calculation is satisfactorily; for higher mass losses, which are not important regarding practical applications, the data deviate and a solid residue was also formed $(8 \%$ at complete conversion) ${ }^{24}$

\subsection{Isothermal thermogravimetrical analysis at $\mathrm{HV}$ with a magnetic suspension balance}

The isothermal TGA was conducted with a magnetic suspension balance in a wide pressure range from $\mathrm{HV}\left(10^{-5} \mathrm{~Pa}\right)$ to ambient pressure. Fig. 4 depicts the strong influence of the total pressure on the rate of mass loss of [EMIM] $\left[\mathrm{MeSO}_{3}\right]$ and [EMIM] $\left[\mathrm{NTf}_{2}\right]$.

The dashed lines in Fig. 4 represent the evaporation by ordinary diffusion (eqn (1)) or by the free flight of the vapour molecules (effusion, eqn (7)). The agreement of the measurement and the calculation by eqn (8) is excellent. As expected, decomposition does not play a role at the relative low temperatures of $153^{\circ} \mathrm{C}\left([\mathrm{EMIM}]\left[\mathrm{MeSO}_{3}\right]\right)$ and $104^{\circ} \mathrm{C}\left([\mathrm{EMIM}]\left[\mathrm{NTf}_{2}\right]\right)$.

For a rough estimation of the pressure regimes, where either eqn (1) (ordinary diffusion) or eqn (7) (effusion) are valid, the following approximation for the diffusion coefficient is useful:

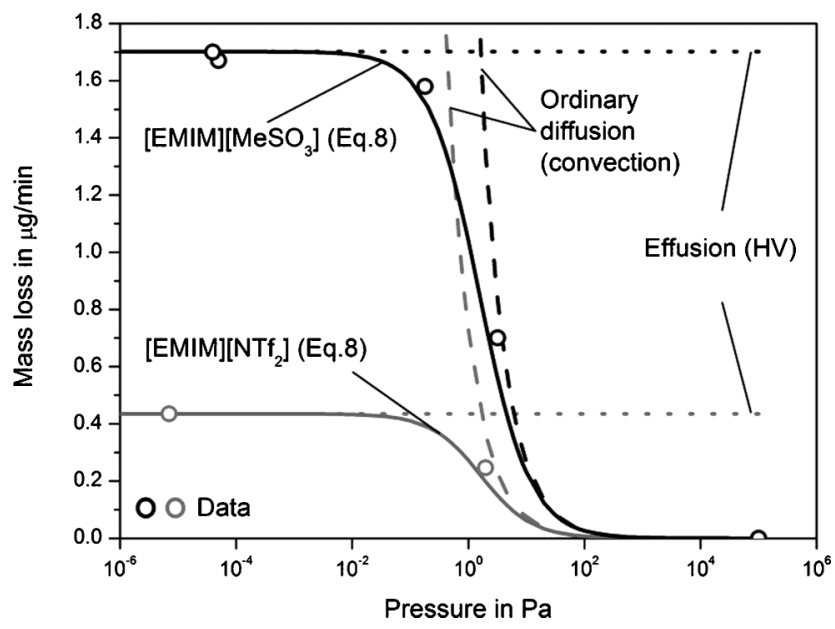

Fig. 4 Isothermal thermogravimetrical analysis in the magnetic suspension balance at $\mathrm{HV}$ (about $10^{-5} \mathrm{~Pa}$ ) with [EMIM] $\left[\mathrm{MeSO}_{3}\right]\left(153^{\circ} \mathrm{C}\right.$, $\left.h_{\mathrm{F}, 0}=4 \mathrm{~mm}\right)$ and $[\mathrm{EMIM}]\left[\mathrm{NTf}_{2}\right]\left(104{ }^{\circ} \mathrm{C}, h_{\mathrm{F}, 0}=3.5 \mathrm{~mm}\right)$. The dashed lines show the limiting cases of evaporation only by ordinary diffusion (eqn (1) and eqn (2) for $R e_{\mathrm{d}}=0$ and $S h_{\mathrm{d}}=1$, see ref. 24) or only by the free flight of the vapour molecules (effusion, eqn (7)), respectively.

$$
D_{\mathrm{g}} \approx \frac{1}{3} u_{\mathrm{mol}} \Lambda
$$

The mean velocity of the molecules, $u_{\text {mol }}$, is given by eqn (5), and the mean free path $(\Lambda)$ is

$$
\Lambda=\frac{1}{\sqrt{2}} \frac{k T}{\sigma p_{\text {total }}}
$$

with $k$ as the Boltzmann constant $\left(1.38 \times 10^{-23} \mathrm{~J} \mathrm{~K}^{-1}\right)$ and $\sigma$ as the collision cross-section of the molecules $\left(\sigma=d^{2}\right.$ for hard spheres with $d$ as diameter). The eqn (7) to (10) yield:

$$
-\left.\frac{\mathrm{d} m_{i}}{\mathrm{~d} t}\right|_{\text {evaporation }}=\left(\frac{3}{4} \frac{d_{\mathrm{C}}}{S h_{\mathrm{d}} \Lambda}+1\right)^{-1} \sqrt{\frac{M_{i} R T}{2 \pi}} A_{\mathrm{C}} \frac{p_{\text {vap }, i}}{R T}
$$

The following values are valid for the MSB: ${ }^{12,24} S h_{\mathrm{d}} \approx 1, d_{\mathrm{C}}=$ $1.6 \mathrm{~cm}$, and $\Lambda$ at $1 \mathrm{bar}$ is in the order of magnitude of $10^{-7} \mathrm{~m}$, i.e. $\Lambda \approx 0.01 \mathrm{~m} \mathrm{~Pa} / p_{\text {total }}$. So eqn (11) leads to

$$
-\left.\frac{\mathrm{d} m_{i}}{\mathrm{~d} t}\right|_{\text {evaporation }} \approx\left(\frac{1}{p_{\text {total }}+1}\right) \sqrt{\frac{M_{i} R T}{2 \pi}} A_{\mathrm{C}} \frac{p_{\text {vap }, i}}{R T}
$$

According to eqn (12) the rate of evaporation is reduced by $50 \%$ compared to the maximum rate at $\mathrm{HV}$, if a total pressure of $1 \mathrm{~Pa}$ is reached. This rough estimation is in good agreement with Fig. 4. So for $p_{\text {total }} \ll 1 \mathrm{~Pa}$, the mass loss is completely determined by the free flight of the vapour molecules (eqn (7)), and for $p_{\text {total }} \gg 1 \mathrm{~Pa}$, ordinary diffusion dominates the mass loss by evaporation (eqn (1)). This simple estimation also explains why Earle $e t$ al. found during their distillation experiments with $\left[\mathrm{C}_{6} \mathrm{MIM}\right]\left[\mathrm{NTf}_{2}\right]$ in a sublimation apparatus $\left(\right.$ at $200{ }^{\circ} \mathrm{C}$ ) that the distillation rate is not measurable at 0.83 bar and increases by a factor of five if the total pressure is decreased from $7 \mathrm{~Pa}$ to values below $0.1 \mathrm{~Pa}^{5}$ 
Table 3 Parameters of vaporisation (eqn (2)) as determined by TGA at ambient pressure in overflow of an inert gas $\left(\mathrm{TG}_{\mathrm{ap}}\right)$ and by a magnetic suspension balance at $\mathrm{HV}\left(\mathrm{MSB}_{\mathrm{HV}}\right)$

\begin{tabular}{|c|c|c|c|c|c|c|c|}
\hline \multirow[b]{2}{*}{ Ionic liquid } & \multicolumn{2}{|l|}{$\mathrm{TG}_{\mathrm{ap}}$} & \multicolumn{2}{|l|}{$\mathrm{MSB}_{\mathrm{HV}}$} & \multicolumn{3}{|c|}{ Recommended values $^{a}$} \\
\hline & $C_{\text {vap }}$ in $\mathrm{Pa}$ & $\Delta_{\text {vap }} H$ in $\mathrm{kJ} \mathrm{mol}^{-1}$ & $C_{\text {vap }}$ in $\mathrm{Pa}$ & $\Delta_{\text {vap }} H$ in $\mathrm{kJ} \mathrm{mol}^{-1}$ & $C_{\text {vap }}$ in $\mathrm{Pa}$ & $\Delta_{\text {vap }} H$ in $\mathrm{kJ} \mathrm{mol}^{-1}$ & $p_{\text {vap }, 500 \mathrm{~K}}$ in $\mathrm{Pa}$ \\
\hline$[\mathrm{EMIM}]\left[\mathrm{NTf}_{2}\right]$ & $2.2 \times 10^{12}$ & 123 & $9.7 \times 10^{10}$ & 116 & $3.5 \times 10^{11}$ & 120 & 0.10 \\
\hline$[\mathrm{BMIM}]\left[\mathrm{NTf}_{2}\right]^{b}$ & $2.2 \times 10^{12}$ & 122 & $1.5 \times 10^{14}$ & 136 & $1.4 \times 10^{13}$ & 130 & 0.37 \\
\hline$[\mathrm{EMIM}]\left[\mathrm{MeSO}_{3}\right]$ & not measurable at $1 \mathrm{bar}$ & not measurable at 1 bar & $7.5 \times 10^{12}$ & 141 & $7.5 \times 10^{12}$ & 141 & 0.014 \\
\hline$[\mathrm{EMIM}]\left[\mathrm{CF}_{3} \mathrm{SO}_{3}\right]$ & not measurable at 1 bar & not measurable at 1 bar & $5.6 \times 10^{12}$ & 140 & 5.6. $\times 10^{12}$ & 140 & 0.013 \\
\hline
\end{tabular}

${ }^{a}$ For [EMIM] [NTf $f_{2}$ and [BMIM][NTf $\left.{ }_{2}\right]$, data of evaporation were determined by both experimental methods; then all data were used for the fitting. If not, data of the MSB at HV were used. ${ }^{b}$ Already published in previous papers. ${ }^{12,13}$

Fig. 5 compares the plot of the vapour pressure equation derived by the simulation of the ambient pressure TG measurements (overflow of $\mathrm{He}$ and $\mathrm{N}_{2}$ at $0.1 \mathrm{~K} \mathrm{~min}^{-1}$ ) with the results obtained in the MSB at $\mathrm{HV}$ for $[\mathrm{EMIM}]\left[\mathrm{NTf}_{2}\right]$ and $[\mathrm{BMIM}]\left[\mathrm{NTf}_{2}\right]$. The agreement is satisfactory. The mean values of $C_{\text {vap }}$ and $\Delta_{\text {vap }} H$, which best represent the vapour pressure in
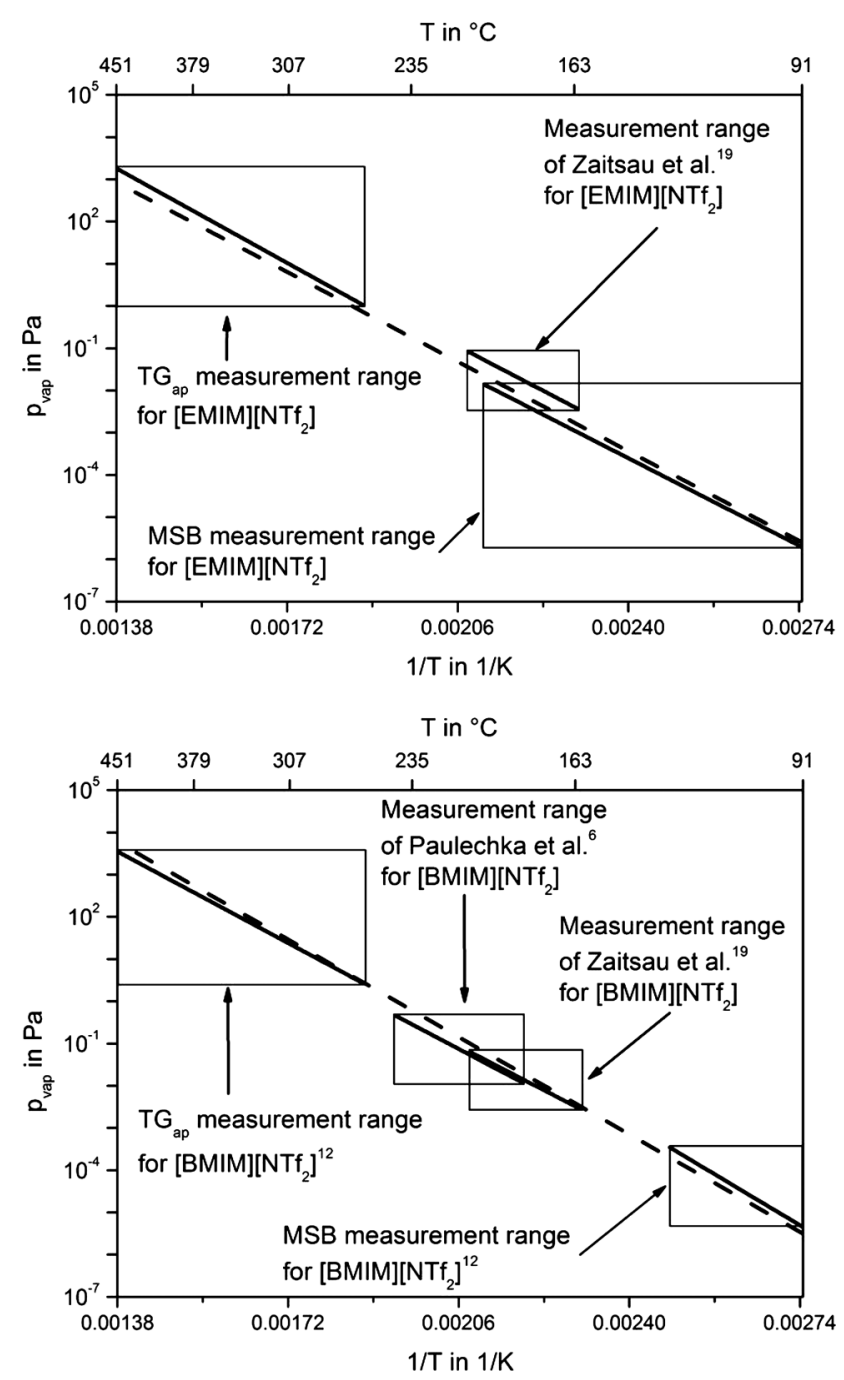

Fig. 5 Vapour pressure of [EMIM] $\left[\mathrm{NTf}_{2}\right]$ and $[\mathrm{BMIM}]\left[\mathrm{NTf}_{2}\right]$ based on MSB and $\mathrm{TG}_{\mathrm{ap}}$ (this work) and comparison with literature data., ${ }^{6,19}$ The solid lines represent the $p_{\text {vap }}$-equation based on each method and the dashed lines the recommended values considering both the data obtained by the MSB and $\mathrm{TG}_{\text {ap }}$ (see Table 3 ). the whole temperature range $\left(90\right.$ to $\left.400{ }^{\circ} \mathrm{C}\right)$, are listed in Table 3 as "recommended values". The deviation of the recommended vapour pressure equation to the experimental data either measured by the MSB of the $\mathrm{TG}_{\mathrm{ap}}$ can be characterized by a factor of about 1.5, i.e. for a calculated vapour pressure of for example $15 \mathrm{~Pa}$, the "true" value is in a range of 10 to $23 \mathrm{~Pa}$. The data measured by Zaitsau et al. and Paulechka et al. by the effusion Knudsen method are also shown in Fig. 5. ${ }^{6,19}$ The agreement is also satisfactory, which is also confirmed by the comparison of the enthalpy of vaporisation (this work $130 \mathrm{~kJ}$ $\mathrm{mol}^{-1}$ for BMIM] $\left.\left[\mathrm{NTf}_{2}\right]\right)$ with the values of Zaitsau et al. $(118 \mathrm{~kJ}$ $\mathrm{mol}^{-1}$ at $\left.204{ }^{\circ} \mathrm{C}\right)$ and Paulechka $\left(120 \mathrm{~kJ} \mathrm{~mol}^{-1}, 214{ }^{\circ} \mathrm{C}\right),{ }^{6,19}$ and data given by Boesmann and Wasserscheid ${ }^{25}\left(110 \mathrm{~kJ} \mathrm{~mol}^{-1}\right.$ at $300{ }^{\circ} \mathrm{C}, 125 \mathrm{~kJ} \mathrm{~mol}^{-1}, 20^{\circ} \mathrm{C}$ ).

Based on the entropy term of the vapour pressure equation $\left(C_{\text {vap }}\right.$, eqn (8)), which is related to the reference pressure of 1 $\mathrm{Pa}$, the standard vaporisation entropy $\Delta_{\text {vap }} S^{0}$ for the standard pressure $p^{0}$ of $10^{5} \mathrm{~Pa}$ can be estimated as follows:

$$
\Delta_{\text {vap }} S^{0} \approx \Delta_{\text {vap }} S_{1 \mathrm{~Pa}}-R \ln \left(\frac{p^{0}}{p_{\text {ref }}}\right)=R \ln \left(\frac{C_{\text {vap }}}{10^{5}}\right)
$$

The values of the standard vaporisation entropy $\Delta_{\text {vap }} S^{0}$ (in this work assumed to be constant, i.e. approximately representative for a mean temperature of $500 \mathrm{~K}$ ) of the investigated ILs are listed in Table 4 and compared with literature data. The values estimated in this work are close to the value for [BMIM] $\left[\mathrm{PF}_{6}\right]$ calculated from the results of calorimetric measurements and statistical thermodynamic calculations in the ref. 25 and 26. For the calculations the vapour for $[\mathrm{BMIM}]\left[\mathrm{PF}_{6}\right]$ was assumed to consist of ionic pairs. The values given by Zaitsau et al. ${ }^{19}$ for $[\mathrm{EMIM}]\left[\mathrm{NTf}_{2}\right]$ and $[\mathrm{BMIM}]\left[\mathrm{NTf}_{2}\right]$ are also close to the values of this work (Table 4).

Table 4 Standard vaporisation entropy $\Delta_{\text {vap }} S^{0}$ of the investigated ionic liquids (at $500 \mathrm{~K}$ ) estimated in this work and comparison with values given in the literature ${ }^{7,19}$

\begin{tabular}{|c|c|c|c|}
\hline \multirow[b]{2}{*}{ Ionic liquid } & \multicolumn{3}{|c|}{$\Delta_{\text {vap }} S^{0}$ in $\mathrm{J} \mathrm{mol}^{-1} \mathrm{~K}^{-1}$} \\
\hline & This work & Zaitsau et al. ${ }^{19}$ & Paulechka et al. ${ }^{7}$ \\
\hline$[\mathrm{EMIM}]\left[\mathrm{NTf}_{2}\right]$ & 125 & 131 (at $463 \mathrm{~K}$ ) & - \\
\hline$[\mathrm{BMIM}]\left[\mathrm{NTf}_{2}\right]$ & 156 & 127 (at $468 \mathrm{~K}$ ) & - \\
\hline$[\mathrm{EMIM}]\left[\mathrm{MeSO}_{3}\right]$ & 151 & - & - \\
\hline$[\mathrm{EMIM}]\left[\mathrm{CF}_{3} \mathrm{SO}_{3}\right]$ & 148 & - & - \\
\hline$[\mathrm{BMIM}]\left[\mathrm{PF}_{6}\right]$ & - & - & 150 (at $500 \mathrm{~K}$ ) \\
\hline
\end{tabular}


In principle, the rate of decomposition can also be measured by the MSB if the pressure is increased to 1 bar. The Arrhenius plot (Fig. 6) of the rate constant of decomposition of [EMIM] $\left[\mathrm{MeSO}_{3}\right]$ and [EMIM] $\left[\mathrm{CF}_{3} \mathrm{SO}_{3}\right]$ based on ambient pressure measurements in overflow of an inert gas and the values obtained by the magnetic suspension balance at 1 bar are in good agreement. For the equipment used in this work, the TGA with an overflow of a gas is preferable to determine kinetic parameters of decomposition because of the lower operating expenditures. In addition, the gas phase is stagnant in the MSB and thus free convection and probably also recondensation may disturb the measurements (see footnote $c$ of Table 2).

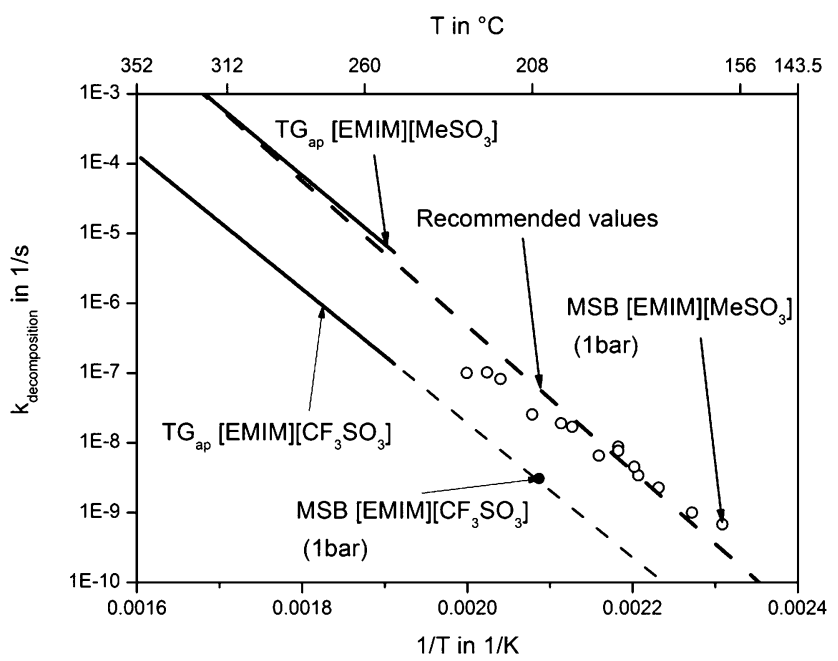

Fig. 6 Arrhenius plot of the rate constant of thermal decomposition of [EMIM] $\left[\mathrm{MeSO}_{3}\right]$ and [EMIM] $\left[\mathrm{CF}_{3} \mathrm{SO}_{3}\right]$ based on ambient pressure measurements in overflow of an inert gas and in the magnetic suspension balance at 1 bar. Recommended values of $[\mathrm{EMIM}]\left[\mathrm{MeSO}_{3}\right]$ characterise the best fit of TG and MSB data at 1 bar.

For $[\mathrm{EMIM}]\left[\mathrm{NTf}_{2}\right]$ and $[\mathrm{BMIM}]\left[\mathrm{NTf}_{2}\right]$, the rate of evaporation in the MSB is even at ambient pressure still too high to detect a contribution of decomposition (see secction 4.3), at least for $T<300{ }^{\circ} \mathrm{C}$, which is the temperature limit at $\mathrm{HV}$ of the MSB used in this work.

\subsection{Proposal of a reasonable approach to determine the volatility and stability of ILs}

The Fig. 7 and 8 show the calculated rates of mass loss by evaporation and decomposition for $[\mathrm{EMIM}]\left[\mathrm{NTf}_{2}\right]$ and [EMIM] $\left[\mathrm{MeSO}_{3}\right]$ at typical conditions of the MSB ( $\left.\mathrm{HV}, 1 \mathrm{bar}\right)$ and of the TG in overflow of $\mathrm{N}_{2}$. Fig. 7 represents the case of an IL with a relative high stability compared to the volatility using [EMIM] $\left.\left[\mathrm{NTf}_{2}\right)\right]$ as example, and Fig. 8 represents the reverse case of an IL with a relative low stability using $[\mathrm{EMIM}]\left[\mathrm{MeSO}_{3}\right]$ as example.

Based on these two different cases depicted in Fig. 7 and Fig. 8, a general strategy can be derived that may help in future to determine efficiently and reliably the volatility (vapour pressure equation) and the stability (kinetics of decomposition) of ILs. Two limiting values of the mass loss are also shown in the Fig. 7 and 8. At first, the rate of mass loss must be higher than the detection limit. For the $\mathrm{TG}_{\text {ap }}$ used in this work this is $1 \mu \mathrm{g}$
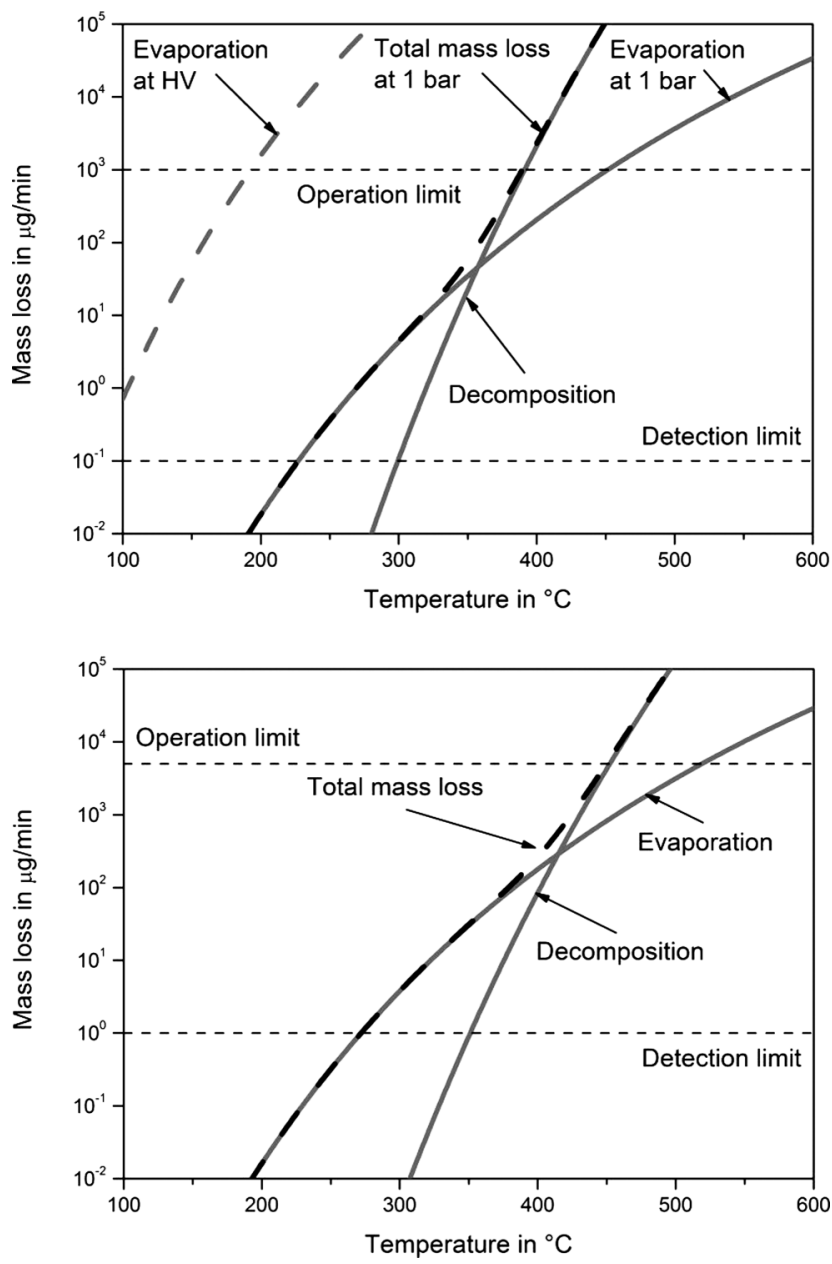

Fig. 7 Diagram to illustrate the strategy to determine the volatility and stability of an IL with a high thermal stability and high volatility by TGA (calculated mass loss by evaporation and decomposition of [EMIM] $\left[\mathrm{NTf}_{2}\right.$ ] for typical conditions of the MSB (top, HV and 1 bar, $1 \mathrm{~g} \mathrm{IL}$ ) and for the TG (below, $40 \mathrm{mg} \mathrm{IL}$ ) in overflow of an inert gas (here $\mathrm{N}_{2}$ ). Note that the calculations were done assuming a constant mass.

$\min ^{-1}$ and for the MSB $0.1 \mu \mathrm{g} \mathrm{min}{ }^{-1}$. Secondly, the rate of mass loss must be lower than the indicated operation limit, which is given by the maximum rate that is reached before the sample is rapidly gone by evaporation and/or decomposition. For the $\mathrm{TG}_{\mathrm{ap}}$, the temperature interval, where most of the mass loss occurs, is around $100 \mathrm{~K}$ between 280 and $380{ }^{\circ} \mathrm{C}$ (e.g. Fig. 2). At the highest heating rate of $10 \mathrm{~K} \mathrm{~min}^{-1}$ this corresponds to an effective reaction time of $8 \mathrm{~min}^{24}$ The (initial) mass of the sample is around $40 \mathrm{mg}$, which leads to a maximum detectable rate of mass loss of $5000 \mu \mathrm{g} \mathrm{min}{ }^{-1}$ (= $40 \mathrm{mg}$ per $8 \mathrm{~min}$ ). For the isothermal MSB at least 4 values of the rate should be measured (each at different temperatures) to determine the vapour pressure equation or the parameters of decomposition at ambient pressure. According to experience, each measurement takes at least $4 \mathrm{~h}$, i.e. $16 \mathrm{~h}$ in total. With the initial mass of $1 \mathrm{~g}$ this leads to a limiting rate of about $1000 \mu \mathrm{g} \min ^{-1}(\approx 1 \mathrm{~g}$ per $16 \mathrm{~h}$ ). Higher rates than these operation limits can hardly be reached for the equipment used in this work, because the crucibles in the $\mathrm{TG}_{\mathrm{ap}}$ and in the MSB would then be emptied very quickly. 

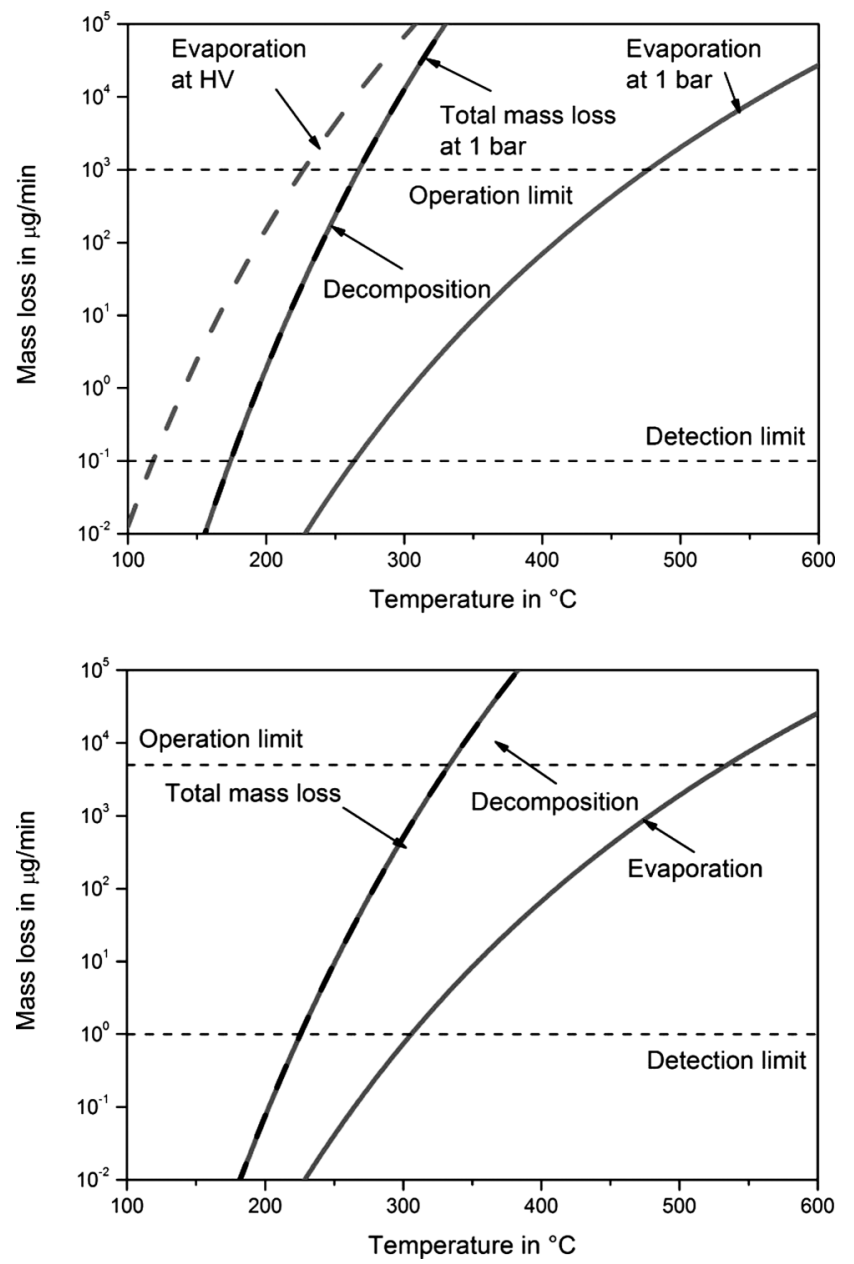

Fig. 8 Diagram to illustrate the strategy to determine the volatility and stability of an IL with a low thermal stability and low volatility by TGA (calculated mass loss by evaporation and decomposition of [EMIM] $\left[\mathrm{MeSO}_{3}\right.$ ] for typical conditions of the MSB (top, HV and 1 bar, $1 \mathrm{~g} \mathrm{IL}$ ) and for the TG (below, $40 \mathrm{mg}$ IL) in overflow of an inert gas (here $\mathrm{N}_{2}$ ). Note that the calculations were done assuming a constant mass.

In case of a high thermal stability (or a relative high volatility), evaporation can be measured by the MSB at HV and also by the $\mathrm{TG}$ at ambient pressure (Fig. 7). If $\mathrm{HV}$ is available, the vapour pressure should be determined at $\mathrm{HV}$, because the simple eqn (7) can then be used and a $S h$-correlation and the knowledge of the diffusion coefficient of the IL vapour molecules (ionic pairs) in the gas is then not needed as for ordinary diffusion (eqn (1)). But, the decomposition kinetics can then only be determined by $\mathrm{TG}_{\mathrm{ap}}$ (overflow of inert gas), and a high heating rate should then be chosen to get into the regime where decomposition plays a role or dominates the total rate of mass loss (Fig. 7, below, $T>$ $400^{\circ} \mathrm{C}$ ).

In case of a low thermal stability (and relative low volatility), evaporation can only be measured at HV (here with the MSB) and not at ambient pressure (Fig. 8). Thus, a HV apparatus is needed. The decomposition kinetics can then be measured at ambient pressure either by $\mathrm{TG}_{\text {ap }}$ (overflow of inert gas) or by a MSB. Because of the simplicity of the measurement and the operating expenditures, a "simpler" $\mathrm{TG}_{\mathrm{ap}}$ is then the method of choice.
Two other combinations of the strength of the thermal stability and of the vapour pressure not discussed in the Fig. 7 and 8 are also possible, whereby we assume that the activation energy of decomposition is higher compared to the enthalpy of evaporation:

- For ILs with a low thermal stability and high volatility, the vapour can at least in principle only be measured at low temperatures, at which evaporation compared to decomposition is favoured. Hence, the method of choice is effusion at $\mathrm{HV}$ with a device such as a MSB, but we then may be limited by room temperature, if no cooling of the MSB is possible.

- For ILs with a high thermal stability and relative low volatility, only the vapour pressure can be determined by HV effusion experiments within the limits of the MSB with regard to the maximum experimentally allowable temperature (here $250{ }^{\circ} \mathrm{C}$ ) and detection limit (here $0.1 \mu \mathrm{g} \mathrm{min}{ }^{-1}$ ). The kinetic parameters of decomposition are now only measurable at elevated pressure ( $\gg$ vapour pressure in order to lower the evaporation rate) with an apparatus with a very low ratio of surface area for evaporation to the sample volume. Hence, the TGA and MSB used here are inappropriate.

\subsection{Proposal of reasonable criteria for the maximum operation temperature of ILs}

4.4.1 Maximum operation temperature of ILs with regard to thermal decomposition. The comparison of the rate constants of decomposition of the four investigated ILs (Fig. 9, see also Table 2 for the values of the rate constants at $500 \mathrm{~K}$ ) indicates that the stability of [EMIM][NTf $\left.{ }_{2}\right]$ and $[\mathrm{BMIM}]\left[\mathrm{NTf}_{2}\right]$ is by several orders of magnitude higher compared to [EMIM] $\left[\mathrm{MeSO}_{3}\right]$ and [EMIM] $\left[\mathrm{CF}_{3} \mathrm{SO}_{3}\right]$. Fig. 9 also shows data for the decomposition of hexadecane ${ }^{26}$ (mainly to gases) and of anthracene ${ }^{27}$ (mainly to coke), indicating that $[\mathrm{EMIM}]\left[\mathrm{NTf}_{2}\right]$ and $[\mathrm{BMIM}]\left[\mathrm{NTf}_{2}\right]$ are as stable as typical higher hydrocarbons.

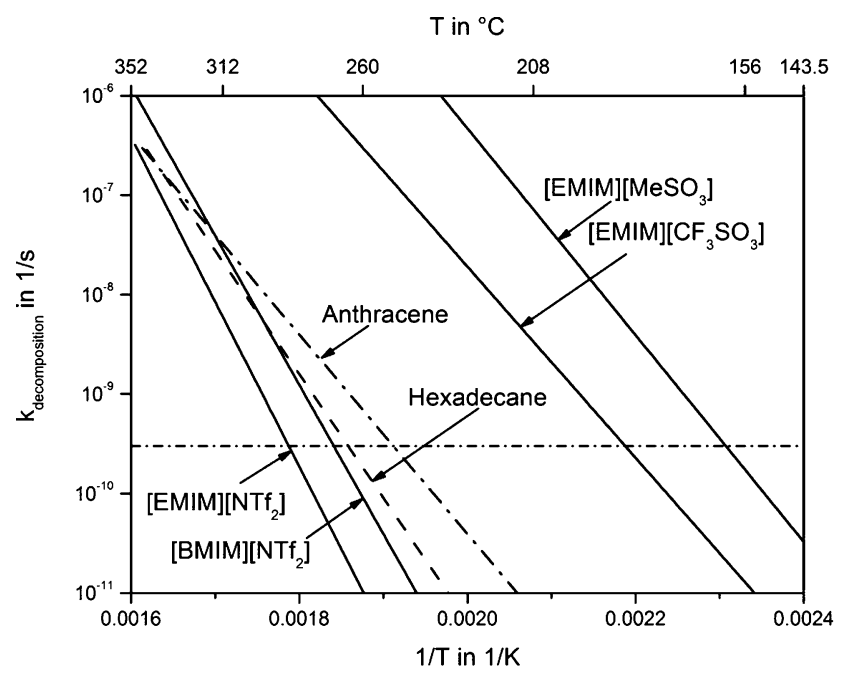

Fig. 9 Rate constants of thermal decomposition of the ILs $\left[\mathrm{EMIM}_{[}\left[\mathrm{NTf}_{2}\right], \quad[\mathrm{BMIM}]\left[\mathrm{NTf}_{2}\right], \quad[\mathrm{EMIM}]\left[\mathrm{MeSO}_{3}\right], \quad\right.$ and $[\mathrm{EMIM}]\left[\mathrm{CF}_{3} \mathrm{SO}_{3}\right]$ (parameters see Table 2). For comparison, data for the thermal decomposition of hexadecane ${ }^{26}$ (mainly to gaseous products) and of anthracene ${ }^{27}$ (mainly to solid coke) are also shown. The dashed-dotted line represent the case of $1 \%$ decomposition per year. 
For technical applications of ILs in closed systems, e.g. as solvent for two-phase catalysis or as extraction agent, the mass loss by evaporation is irrelevant (see below chapter 4.4.2), and only thermal degradation limits the operation temperature. For $T=$ constant, eqn (3) yields:

$$
t_{\text {decomposition }}=\frac{-\ln \left(1-X_{i}\right)}{k_{\text {decomposition }, i}}=\frac{-\ln \left(1-X_{i}\right)}{k_{0, i}} e^{\frac{E_{\mathrm{A}, i}}{R T}}
$$

A criterion for the limit of the operation temperature may be an annual decomposition of $1 \%\left(T_{\max , 1 \% / \mathrm{a}}\right),{ }^{12,13}$ and eqn (14) leads to

$$
T_{\max , 1 \% / \mathrm{a}}=\frac{E_{\mathrm{A}, i}}{R}\left(21.87+\ln k_{0, i}\right)^{-1}
$$

For $[\mathrm{BMIM}]\left[\mathrm{NTf}_{2}\right]$, eqn (15) and the parameters of the rate constant (Table 2) yield a value of $T_{\max , 1 \% / \mathrm{a}}$ of $271{ }^{\circ} \mathrm{C}$. For [EMIM] [NTf ${ }_{2}$, a similar value is obtained $\left(286^{\circ} \mathrm{C}\right)$, whereas for [EMIM] $\left[\mathrm{MeSO}_{3}\right]$ and [EMIM] $\left[\mathrm{CF}_{3} \mathrm{SO}_{3}\right] T_{\max , 1 \% / \mathrm{a}}$ is much lower $\left(161{ }^{\circ} \mathrm{C}\right.$ and $185^{\circ} \mathrm{C}$ ).

If the onset temperature of a TG measurement is used to characterise the maximum allowable temperature, much higher values are reached, and the stability is highly overestimated, e.g. $T_{\text {onset }}$ is about $220{ }^{\circ} \mathrm{C}$ for [EMIM] $\left[\mathrm{MeSO}_{3}\right]$ (Fig. 3), exceeding $T_{\max , 1 \% / \mathrm{a}}$ by ca. $60 \mathrm{~K}$ (Fig. 9). For [EMIM] $\left[\mathrm{NTf}_{2}\right]$ and [BMIM] $\left[\mathrm{NTf}_{2}\right] T_{\text {onset }}$ even only characterises volatility and not thermal stability, at least, if the heating rate is not very high.

For an accurate theoretical analysis of the difference between $T_{\text {onset }}$ and $T_{\max , 1 \% / \mathrm{a}}$ the kinetic parameters of decomposition can be used. Therefore, we assume that $T_{\text {onset }}$ equals the temperature to reach a mass loss of $1 \%$ during a TG experiment $\left(T_{\text {onset } 1 \%}\right)$. If the kinetic parameters are known, $T_{\text {onset, } 1 \%}$ can be calculated as follows. For a constant heating rate eqn (3) yields

$$
-\frac{\mathrm{d} m_{i}}{m_{i}}=\frac{k_{0, i}}{H R} e^{\left(-\frac{E_{\mathrm{A}, i}}{R T}\right)} \mathrm{d} T
$$

and integration (by approximation of the integral, ${ }^{28}$ relative error $<5 \%$ ) leads to

$$
\begin{aligned}
-\ln \left(1-X_{i}\right) & =\frac{k_{0, i}}{H R} \int_{T_{0}}^{T} e^{\left(-\frac{E_{\mathrm{A}, i}}{R T}\right)} \mathrm{d} T \\
& \approx \frac{k_{0, i} R T^{2}}{H R E_{\mathrm{A}, i}} e^{-\frac{E_{\mathrm{A}, i}}{R T}}\left(1-2 \frac{R T}{E_{\mathrm{A}, i}}\right) \quad\left(\text { for } \frac{E_{\mathrm{A}, i}}{R T}>10\right)
\end{aligned}
$$

Thus, $T_{\text {onset, } 1 \%}$ is given in approximation by

$$
0.01=\frac{k_{0, i} R T_{\mathrm{onset}, 1 \%}^{2}}{H R E_{\mathrm{A}, i}} e^{-\frac{E_{\mathrm{A}, i}}{R T_{\mathrm{onset}, 1 \%}}}\left(1-2 \frac{R T_{\text {onset }, 1 \%}}{E_{\mathrm{A}, i}}\right)
$$

By means of eqn (14) and eqn (18), the "real" limit of the operation temperature, which characterises an isothermal mass loss of $1 \%$ per year $\left(T_{\max , 1 \% / \mathrm{a}}\right)$, and the onset temperature, which characterises $1 \%$ mass loss during a TG experiment can now be calculated and compared. The respective values for the investigated ILs are listed in Table 5 for different heating rates in a range of 0.1 to $10 \mathrm{~K} \mathrm{~min}$. Depending on the heating rate $T_{\text {onset, } 1 \%}$ deviates from $T_{\max , 1 \% / \mathrm{a}}$ by up to $150 \mathrm{~K}$, which makes clear that $T_{\text {onset, } 1 \% / \text { a }}$ should not be used as an indication of the real stability of an IL or of the maximum allowable temperature.

For the investigated ILs, the comparison of $T_{\text {onset, } 1 \%}$ and $T_{\max , 1 \% / \mathrm{a}}$ indicates that the difference is almost constant for a given heating rate, e.g. about $125^{\circ} \mathrm{C}$ for $2 \mathrm{~K} \mathrm{~min}^{-1}$ (Table 5). In order to check, whether this difference can be used to estimate $T_{\text {max, } 1 \% / \mathrm{a}}$ based on $T_{\text {onset } 1 \% \text {, a general equation for the difference }}$ between $T_{\text {onset }}$ and $T_{\max , 1 \% / \mathrm{a}}$ is needed, which can be derived as follows. Eqn (18) and the introduction of the Arrhenius number $\gamma_{\text {onset }}$ (eqn (20)) leads to the equation for the pre-exponential factor $k_{0, i}$ and $\ln \left(k_{0, i}\right)$, respectively:

$$
\ln \left(k_{0, i}\right)=\gamma_{\text {onset }}+\ln \left\{\frac{0.01 H R \gamma_{\text {onset }}^{2}}{T_{\text {onset }, 1 \%}\left(\gamma_{\text {onset }}-2\right)}\right\}
$$

with

$$
\gamma_{\text {onset }}=\frac{E_{\mathrm{A}}}{R T_{\text {onset }, 1 \%}}
$$

Table 5 Comparison of $T_{\text {onset, } 1 \%}$ and $T_{\text {max, } 1 \% / \mathrm{a}}$ calculated based on the kinetic parameters of decomposition (Table 2, recommended values). Note

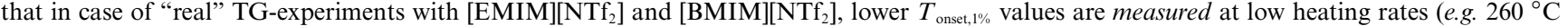
for [EMIM][NTf $\left.{ }_{2}\right]$ at $0.1 \mathrm{~K} \mathrm{~min}^{-1}$, Fig. 2), and not the values given in brackets, because evaporation has a strong influence, but was not considered to calculate $T_{\text {onset, } 1 \%}$

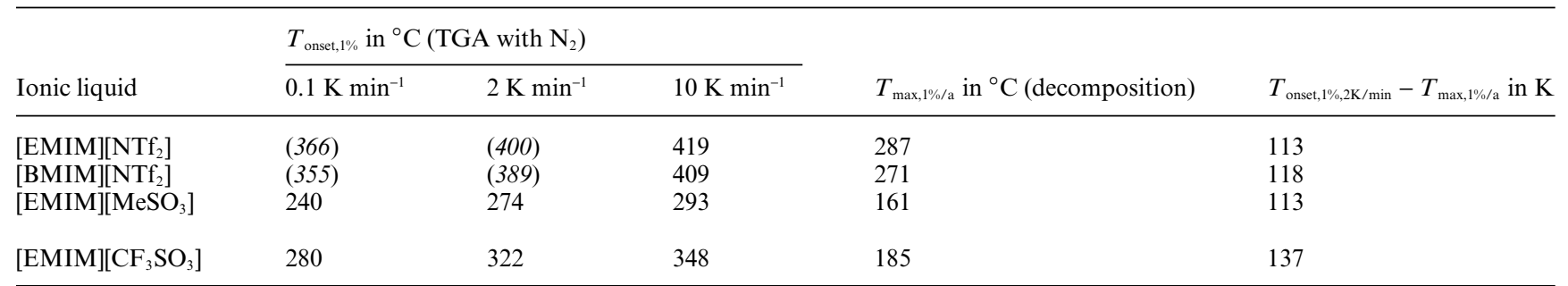


Insertion of eqn (19/20) into eqn (15) yields:

$$
T_{\text {onset }, 1 \%}-T_{\text {max }, 1 \% / a}=T_{\text {onset }, 1 \%}-\frac{T_{\text {onset }, 1 \%} \gamma_{\text {onset }}}{21.87+\gamma_{\text {onset }}+\ln \left\{\frac{0.01 H R \gamma_{\text {onset }}^{2}}{T_{\text {onset }, 1 \%}\left(\gamma_{\text {onset }}-2\right)}\right\}}
$$

For the four ILs, $\gamma_{\text {onset }}$ is 57 for [EMIM][NTf 2 , 52 for [BMIM] $\left.\mathrm{NTf}_{2}\right], 379$ for [EMIM] $\left[\mathrm{CF}_{3} \mathrm{SO}_{3}\right]$, and 4437 for [EMIM] $\left[\mathrm{MeSO}_{3}\right]\left(\mathrm{HR}=2 \mathrm{~K} \mathrm{~min}^{-1}\right)$. If we use average values of 47 for $\gamma_{\text {onset }}$ and $346^{\circ} \mathrm{C}(619 \mathrm{~K})$ for $T_{\text {onset, } 1 \%}$ (Table 5), we again get a difference between $T_{\text {onset }}$ and $T_{\text {max }, 1 \%}\left(\mathrm{HR}=2 \mathrm{~K} \mathrm{~min}^{-1}\right)$ of $121 \mathrm{~K}$.

Fig. 10 shows the graphical presentation of eqn (21) for three different values of $T_{\text {onset, } 1 \%}$ in the range measured for the investigated ILs at a heating rate of $2 \mathrm{~K} \mathrm{~min}^{-1}$. Unfortunately, the difference may vary between 90 and $190 \mathrm{~K}$ and cannot be regarded as constant. The reason that the difference is around $125 \mathrm{~K}$ for the four investigated ILs is caused by an increase of $E_{\mathrm{A}}$ with increasing stability $\left(T_{\text {onset }}\right)$, but this could be a coincidence and not a general rule, at least until not much more ILs have been analysed with regard to decomposition.

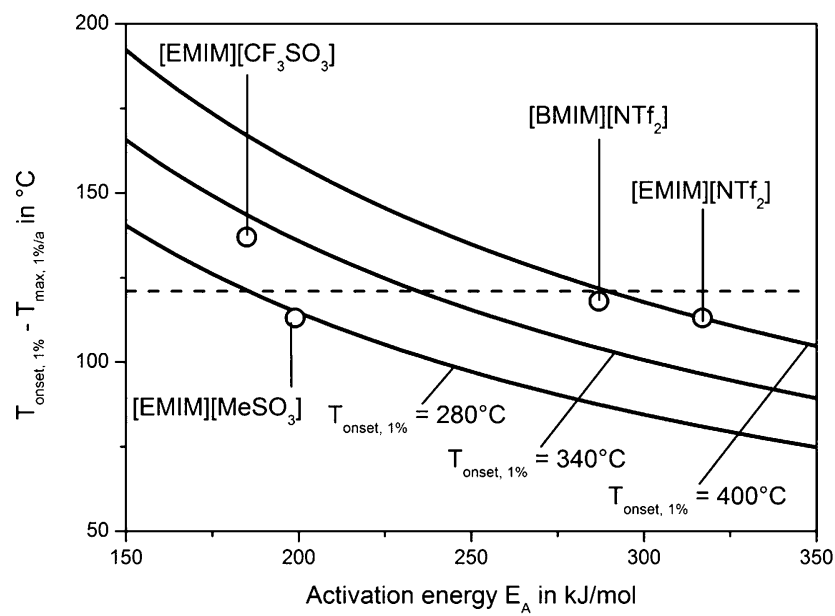

Fig. 10 Influence of the activation energy of decomposition on the difference between the temperature that characterises an isothermal mass loss of $1 \% / \mathrm{a}\left(T_{\max , 1 \% / \mathrm{a}}\right)$, and of the onset temperature, which characterises $1 \%$ mass loss during a TG experiment at a heating rate of $2 \mathrm{~K} \mathrm{~min}^{-1}$ ( $\left.T_{\text {onset, } 1 \%}\right)$. Calculation based on eqn (21). Dotted line: average value for the four investigated ILs.

In some cases, the criterion for the limit of the operation temperature of an annual decomposition of $1 \%\left(T_{\max , 1 \% / \mathrm{a}}\right)$ may be too strict, e.g. for technical processes with relatively cheap ILs or for researchers who investigate chemical data of ILs such as the viscosity or - as in this work - the vapour pressure at elevated temperatures within in a limited time of, say, a day. In addition, a decomposition of $1 \%$ may not necessarily alter the chemical and/or physical properties of an IL so strongly that the IL cannot be used any longer, e.g. as a solvent. Rewriting of eqn (14) leads to a more general equation to estimate $T_{\max }$ :

$$
\begin{aligned}
T_{\max } & =\frac{E_{\mathrm{A}, i}}{R} \frac{1}{\ln \left\{\frac{k_{0, i} t_{\text {decomposition }}}{-\ln \left(1-X_{\text {max }, i}\right)}\right\}} \\
& \approx \frac{E_{\mathrm{A}, i}}{R} \frac{1}{\ln \left\{k_{0, i} \frac{t_{\text {decomposition }}}{X_{\text {max }, i}}\right\}}
\end{aligned}
$$

Fig. 11 shows the influence of the relevant treatment (decomposition) time $t_{\text {decomposition }}$ on the maximum operation temperature $T_{\max }$ with regard to thermal degradation for [EMIM] $\left[\mathrm{CF}_{3} \mathrm{SO}_{3}\right]$ as example. For the strict criterion of only $1 \%$ decomposition per year, $T_{\max }$ is $185^{\circ} \mathrm{C}$, but for example for a limit of $5 \%$ per day, $T_{\text {max }}$ is $269^{\circ} \mathrm{C}$. However, $T_{\text {onset }}$ is still lower, see Table 5.

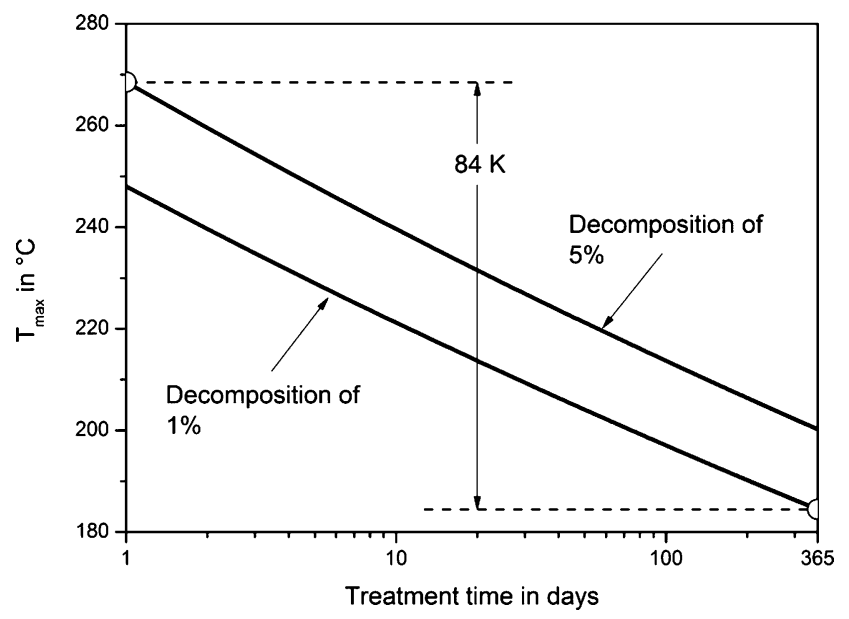

Fig. 11 Influence of the treatment (decomposition) time on the maximum operation temperature of an IL with regard to degradation taking $[\mathrm{EMIM}]\left[\mathrm{CF}_{3} \mathrm{SO}_{3}\right]$ as example.

4.4.2 Maximum operation temperature of ILs with regard to evaporation. The comparison of the vapour pressures show that $[\mathrm{EMIM}]\left[\mathrm{NTf}_{2}\right]$ and $[\mathrm{BMIM}]\left[\mathrm{NTf}_{2}\right]$ are by an order of magnitude more volatile than [EMIM] $\left[\mathrm{MeSO}_{3}\right]$ and [EMIM] $\left[\mathrm{CF}_{3} \mathrm{SO}_{3}\right]$ (Fig. 12, see also Table 3 for $p_{\text {vap }}$ at $500 \mathrm{~K}$ ). For comparison, the vapour pressure data of hexadecane, ${ }^{29}$ anthracene (sublimation), ${ }^{29}$ and zinc (sublimation) ${ }^{30}$ are also shown, indicating that even a relative volatile IL like $[\mathrm{BMIM}]\left[\mathrm{NTf}_{2}\right]$ still has a vapour pressure that is four orders of magnitude lower compared to high boiling hydrocarbons. For the temperature range of this work, the vapour pressures of $[\mathrm{EMIM}]\left[\mathrm{NTf}_{2}\right]$ and $[\mathrm{BMIM}]\left[\mathrm{NTf}_{2}\right]$ are one to two orders of magnitude higher than those of [EMIM] $\left[\mathrm{MeSO}_{3}\right]$ and $[\mathrm{EMIM}]\left[\mathrm{CF}_{3} \mathrm{SO}_{3}\right]$. It is interesting to note that the vapour pressure of $[\mathrm{EMIM}]\left[\mathrm{NTf}_{2}\right]$ is slightly lower than [BMIM] $\left[\mathrm{NTf}_{2}\right]$. According to the distillation rates $\left(300^{\circ} \mathrm{C}, 10 \mathrm{~Pa}\right)$ measured by Earle et al. in a Kugelrohr apparatus, $p_{\text {vap }}$ increases in the order $[\mathrm{EMIM}]\left[\mathrm{NTf}_{2}\right]>\left[\mathrm{C}_{10} \mathrm{MIM}\right]\left[\mathrm{NTf}_{2}\right]>\left[\mathrm{C}_{16} \mathrm{MIM}\right]\left[\mathrm{NTf}_{2}\right]$, i.e. $p_{\text {vap }}$ decreases with increasing length of the alkyl chain of the cation. ${ }^{5}$ Unfortunately, [BMIM] $\left[\mathrm{NTf}_{2}\right]$ was not investigated by Earle et al., but according to their and our measurements, $p_{\text {vap }}$ should have a maximum for $[\mathrm{BMIM}]\left[\mathrm{NTf}_{2}\right]$. Further experiments will be conducted to clarify this point. 


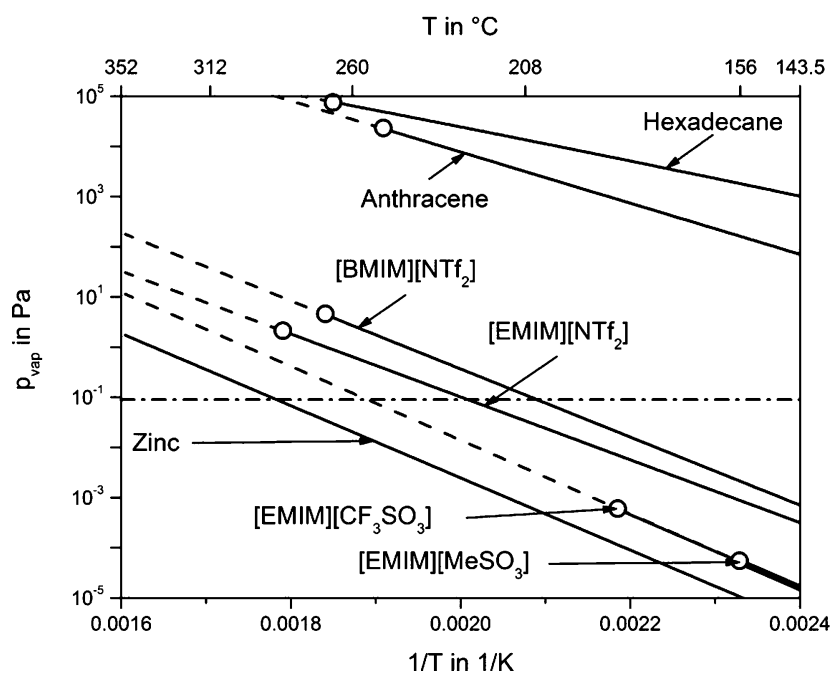

Fig. 12 Vapour pressure of the investigated ILs [EMIM][NTf ${ }_{2}$, [BMIM] $\left[\mathrm{NTf}_{2}\right]$, [EMIM] $\left[\mathrm{CF}_{3} \mathrm{SO}_{3}\right]$ and [EMIM] $\left[\mathrm{MeSO}_{3}\right]$ (for parameters see Table 3). For comparison, values of hexadecane, ${ }^{29}$ anthracene (sublimation), ${ }^{29}$ and of zinc (sublimation) ${ }^{30}$ are also shown. The horizontal dashed-dotted line represents the limit for gas stripping (assumption: $100 \mathrm{~m}_{\text {gas }}^{3}$ per $\mathrm{h}$ and $\mathrm{m}_{\mathrm{IL}}^{3}, 1 \%$ mass loss/a, see text below under "case III"). The lines for [EMIM] $\left[\mathrm{CF}_{3} \mathrm{SO}_{3}\right]$ and [EMIM] $\left[\mathrm{MeSO}_{3}\right]$ are very similar and undistinguishable. The circles indicate the maximum operation temperature with regard to thermal degradation $\left(T_{\max , 1 \% / \mathrm{a}}\right)$.

The extremely low vapour pressure of ILs can also be illustrated by the computed normal boiling temperature by extrapolation of the vapour pressure equation (eqn (2)) with the parameters given in Table 3. For the investigated ILs, $T_{\text {boil, } 1 \text { bar }}$ is around $600^{\circ} \mathrm{C}$ ([EMIM] $\left[\mathrm{NTf}_{2}\right]: 685^{\circ} \mathrm{C}$, [BMIM] $\left[\mathrm{NTf}_{2}\right]: 561^{\circ} \mathrm{C}$, [EMIM] $\left[\mathrm{MeSO}_{3}\right]: 662{ }^{\circ} \mathrm{C}$, and [EMIM] $\left[\mathrm{CF}_{3} \mathrm{SO}_{3}\right]: 671^{\circ} \mathrm{C}$ ). For comparison: for hexadecane, anthracene and zinc, the values are $287^{\circ} \mathrm{C}, 340{ }^{\circ} \mathrm{C}$, and $907{ }^{\circ} \mathrm{C}$.

Now the question arises, whether and under which circumstances not only thermal degradation but also evaporation may limit the maximum operation temperature of an IL. An attempt to give an answer may be given by the inspection of the following three cases: (I) storage in a closed or (II) open vessel with a stagnant gas phase, and (III) the flow of a gas through an IL, which represents the situation of the regeneration of ILs used for extraction or absorption. The latter case could be also important for novel catalytic processes, where solid catalysts or porous supports are coated with an IL to improve the selectivity of heterogeneous catalysts ${ }^{31}$ or to immobilise a homogeneous catalyst, which is dissolved in the thin film of the IL. ${ }^{32-34}$

As an instructive example, the behaviour of [BMIM] $\left[\mathrm{NTf}_{2}\right]$, which is the IL with the highest volatility, is analysed with regard to mass loss by evaporation only. The temperature is fixed to $271{ }^{\circ} \mathrm{C}$, i.e. to $T_{\text {max }, 1 \% / a}$ regarding decomposition. The relevant data for [BMIM] $\mathrm{NTf}_{2}$ ] are $M_{\mathrm{IL}}=419 \mathrm{~g} \mathrm{~mol}^{-1}, \rho_{\mathrm{IL}}=1.44 \mathrm{~g} \mathrm{~cm}^{-3}$, $D_{\mathrm{IL}, \mathrm{N}_{2}}\left(271^{\circ} \mathrm{C}, 1\right.$ bar $)=0.19 \mathrm{~cm}^{2} \mathrm{~s}^{-1}, p_{\text {vap }}\left(271{ }^{\circ} \mathrm{C}\right)=4.6 \mathrm{~Pa}$.

Case I: [BMIM] $\left[\mathrm{NTf}_{2}\right]$ is stored at $271{ }^{\circ} \mathrm{C}$ in a closed vessel at ambient pressure. The volume of the gas phase equals the volume of the IL. In thermodynamic equilibrium, the molar content of the IL in the gas reaches $0.0046 \%\left(=4.6 \mathrm{~Pa} / 10^{5} \mathrm{~Pa}\right)$, and the ideal gas law yields a mass loss of only $3 \times 10^{-50} \%$ as expected, if one considers that at ambient pressure the volume
Table 6 Estimation of $T_{\max , 1 \% / \mathrm{a}}$ for evaporation only (stripping with a gas, $100 \mathrm{~m}_{\text {gas }}^{3}$ (NTP) per $\mathrm{h}$ and $\mathrm{m}^{3}{ }_{\mathrm{IL}}$ see also text) and for thermal decomposition only

\begin{tabular}{lll}
\hline Ionic liquid & $\begin{array}{l}T_{\text {max, } 1 \% / \mathrm{a}} \text { in }{ }^{\circ} \mathrm{C} \\
\text { (thermal decomposition) }\end{array}$ & $\begin{array}{l}T_{\text {max, } 1 \% / \mathrm{a}} \text { in }{ }^{\circ} \mathrm{C} \\
\text { (evaporation, gas stripping) }\end{array}$ \\
\hline [EMIM][NTf $\left.{ }_{2}\right]$ & 287 & 225 \\
{$[\mathrm{BMIM}]\left[\mathrm{NTf}_{2}\right]$} & 271 & 205 \\
{$[\mathrm{EMIM}]\left[\mathrm{MeSO}_{3}\right]$} & 161 & 256 \\
{$[\mathrm{EMIM}]\left[\mathrm{CF}_{3} \mathrm{SO}_{3}\right]$} & 185 & 257 \\
\hline
\end{tabular}

of a gas is typically by about three orders of magnitude higher compared to a liquid.

Case II: [BMIM] $\left[\mathrm{NTf}_{2}\right.$ ] is stored at $271{ }^{\circ} \mathrm{C}$ and 1 bar in a halffilled open vessel with height $h_{\text {vessel }}$. The mass loss takes place by diffusion into the gas phase (assumed to be of infinite size, so saturation is never reached). If the height of the vessel above the IL $\left(h_{\text {vessel }} / 2\right)$ is taken as effective boundary layer thickness $\delta$ (which almost remains constant, if we limit the calculation to $X_{\mathrm{IL}}<1 \%$ ), eqn (1) yields $(\beta=D / \delta)$ :

$$
\begin{aligned}
& -\frac{\mathrm{d} n_{\mathrm{IL}}}{\mathrm{d} t_{\text {vaporisation }}}=\frac{2 D_{\mathrm{IL}, \mathrm{N}_{2}}}{h_{\text {glass }}} A_{\text {glass }} \frac{p_{\text {vap }, \mathrm{IL}}}{R T} \\
& \Rightarrow X_{\mathrm{IL}}=\left(D_{\mathrm{IL}, \mathrm{N}_{2}} \frac{p_{\text {vap }, \mathrm{LL}}}{R T} \frac{4 M_{\mathrm{IL}}}{h_{\text {glass }}^{2} \rho_{\mathrm{IL}}}\right) t_{\text {vaporisation }}
\end{aligned}
$$

For a height of the vessel of $0.1 \mathrm{~m}$, which may be regarded as a typical laboratory equipment size, the values for [BMIM] $\left[\mathrm{NTf}_{2}\right]$ in $\mathrm{N}_{2}$ (as given above) yield a calculated vaporisation time of 51 days to reach a mass loss by evaporation of $1 \%$. Calculations for lower temperatures, which are more realistic concerning the use of ILs yield 12 years for $200{ }^{\circ} \mathrm{C}, 100000$ years for $100{ }^{\circ} \mathrm{C}$, and 1.8 billion years (!) for $30^{\circ} \mathrm{C}$.

Case III: A gas (e.g. $\mathrm{N}_{2}$ or air) is continuously passed through [BMIM] $\left[\mathrm{NTf}_{2}\right.$ ] at $271^{\circ} \mathrm{C}$ and ambient pressure. The gas leaving the vessel should have reached saturation $\left(p_{\text {vap }}=4.6 \mathrm{~Pa}\right.$ at 1 bar), and so $217 \mathrm{~mol}$ gas per mol IL (16700 $\mathrm{m}_{\text {gas }}^{3}$ (NTP) per $\mathrm{m}_{\mathrm{IL}}^{3}$ ) are needed to reach $1 \%$ mass loss. If the IL would be used in extraction or absorption processes, e.g. for gas drying, ${ }^{35}$ the regeneration of the loaded IL by stripping is needed. As an example, we assume a specific volume rate of the stripping gas of $100 \mathrm{~m}^{3}$ gas $(\mathrm{NTP}) \mathrm{h}^{-1} \mathrm{~m}^{-3}{ }_{\mathrm{IL}}$. Thus, if [BMIM][NTf $\mathrm{N}_{2}$ would be stripped at the maximum temperature to exclude thermal degradation $\left(T_{\max , 1 \% / \mathrm{a}}=271^{\circ} \mathrm{C}\right)$, the vapour pressure of $4.6 \mathrm{~Pa}$ then already leads to a mass loss by evaporation after a stripping time of about 7 days $\left(=16700 \mathrm{~m}_{\text {gas }}^{3}\right.$ per $\mathrm{m}^{3}{ }_{\mathrm{IL}} /\left(100 \mathrm{~m}_{\text {gas }}^{3} \mathrm{~h}^{-1}\right.$ $\left.\mathrm{m}^{-1}{ }_{\mathrm{IL}}\right)=167 \mathrm{~h}$ ). Vice versa, a mass loss of $1 \% / \mathrm{a}$ would be reached at $205^{\circ} \mathrm{C}\left(p_{\text {vap }}=0.09 \mathrm{~Pa}\right.$, i.e. 4.6 Pa/0.09 $\mathrm{Pa} \times 7$ days $\left.\approx 1 \mathrm{a}\right)$. For the given example, this vapour pressure and the corresponding temperature, respectively, can be regarded as the limit (indicated as dashed-dotted line in Fig. 12). So for [BMIM] $\left[\mathrm{NTf}_{2}\right]$ (and also for [EMIM] [NTf 2 , Table 6), $T_{\text {max,operation may be determined }}$ by evaporation and not by thermal degradation, if the IL is in continuous contact with a gas.

For less volatile ILs like [EMIM][MeSO$\left.{ }_{3}\right]$ and [EMIM] $\left[\mathrm{CF}_{3} \mathrm{SO}_{3}\right]$, even stripping with a gas never leads to a considerable loss by evaporation, because $p_{\text {vap }}$ is still less than $0.09 \mathrm{~Pa}$ at $T_{\text {max, } 1 \% / a}$ with regard to decomposition, i.e. the maximum operation temperature regarding degradation is 
lower than the limit with regard to evaporation during stripping (Table 6).

The analysis of case III also explains why the mass loss by evaporation is actually measurable by $\mathrm{TG}_{\mathrm{ap}}$ with volatile ILs like $[\mathrm{EMIM}]\left[\mathrm{NTf}_{2}\right]$ and $[\mathrm{BMIM}]\left[\mathrm{NTf}_{2}\right]$. During a typical TG experiment of the present work, 12 litres of $\mathrm{N}_{2}$ or $\mathrm{He}$ are passed over about $3 \times 10^{-5} \mathrm{~cm}^{3}{ }_{\mathrm{IL}} \mathrm{h}^{-1}$ (at $300^{\circ} \mathrm{C}$ ), which is $4 \times 10^{8} \mathrm{~m}_{\text {gas }}^{3} \mathrm{~h}^{-1}$ $\mathrm{m}^{-3}{ }_{\mathrm{IL}}$, and thus enough to vaporise the IL completely in about a minute, if the gas would be saturated. The real amount of gas needed for evaporation during a TG experiment is of course much higher as the gas is far from saturation.

To summarize the issue of evaporation and maximum operation temperature: During storage of ILs in closed or open vessels, losses by evaporation are negligible, and only thermal decomposition limits the maximum operation temperature. But if relatively volatile ILs like [EMIM] $\left[\mathrm{NTf}_{2}\right]$ and [BMIM] $\left[\mathrm{NTf}_{2}\right]$ are in permanent contact with a gas that flows through or over the IL, mass losses by evaporation have to be considered and may even limit $T_{\max }$.

\subsection{Are ionic liquids superheated fluids?}

The magnetic suspension balance is equipped with an inspection window, but bubble formation was never noticed, even if the vapour pressure of the ILs was much higher than the total pressure. For example, at $180{ }^{\circ} \mathrm{C}$, the vapour pressure of $[\mathrm{BMIM}]\left[\mathrm{NTf}_{2}\right]$ is $10^{-2} \mathrm{~Pa}$ compared to the total pressure under $\mathrm{HV}$ of around $10^{-5} \mathrm{~Pa}$. Consequently, ILs are obviously superheated liquids under $\mathrm{HV}$ conditions, and boiling, i.e. bubble formation, does not occur.

The reason is the surface tension, which suppresses the growth of bubbles. The vapour pressure needed for the existence of a bubble with diameter $d_{\text {bubble }}$ and surface tension $\sigma_{\mathrm{IL}}$ is given by the Laplace equation:

$$
p_{\text {vap,IL }}=p_{\text {bubble }}=p_{\text {total }}+\frac{4 \sigma_{\mathrm{IL}}}{d_{\text {bubble }}}
$$

The surface tension of [BMIM] $\mathrm{NTf}_{2}$ ] at $180^{\circ} \mathrm{C}$ is around 0.025 $\mathrm{N} \mathrm{m}^{-1}$ (estimation by extrapolation of literature values reported for a T-range of $20^{\circ} \mathrm{C}$ to $70{ }^{\circ} \mathrm{C}$, where $\sigma_{\text {IL }}$ decreases from 0.034 to $\left.0.031 \mathrm{~N} \mathrm{~m}^{-1}\right) .{ }^{36}$ Under high vacuum $\left(p_{\text {total }} \rightarrow 0\right)$, the hydrostatic pressure is negligible, and bubbles of, say, $0.1 \mathrm{~mm}$ diameter are formed, if the vapour pressure of the IL exceeds $250 \mathrm{~Pa}$. In contrast, the vapour pressure of $[\mathrm{BMIM}]\left[\mathrm{NTf}_{2}\right]$ at $180{ }^{\circ} \mathrm{C}$ is only about $0.01 \mathrm{~Pa}$, and even at the highest temperature that can be realized without thermal decomposition of about $271^{\circ} \mathrm{C}$ only $3 \mathrm{~Pa}$ are reached. In return, we may calculate the critical bubble diameter needed to create a stable bubble at $180{ }^{\circ} \mathrm{C}$, which yields a fantastic bubble diameter of $10 \mathrm{~m}$ (!). Even if the temperature is increased to the maximum value of about $271{ }^{\circ} \mathrm{C}$ where decomposition may start, the critical bubble diameter would still be $2 \mathrm{~cm}$ (assuming $\sigma_{\mathrm{IL}}\left(271{ }^{\circ} \mathrm{C}\right) \approx 0.018 \mathrm{~N} \mathrm{~m}^{-1}$ ). So, boiling and bubble formation cannot take place with ILs even under HV, and ILs can clearly be regarded as superheated liquids.

\section{Conclusion}

The determination of the vapour pressure of ionic liquids is onerous and the discrimination, whether evaporation is superimposed by thermal degradation, is not an easy task. In this work, thermogravimetric methods are presented and discussed to determine the parameters of decomposition and evaporation. Non-isothermal ambient pressure measurements were carried out with an overflow of inert gases, and isothermal experiments were conducted at high vacuum with a magnetic suspension balance. Four ILs were analysed by both methods.

$[\mathrm{EMIM}]\left[\mathrm{NTf}_{2}\right]$ and $[\mathrm{BMIM}]\left[\mathrm{NTf}_{2}\right]$ are relatively volatile and thus thermal decomposition and the respective kinetic parameters are only measurable at ambient pressure and high temperatures (high heating rates). To the contrary, [EMIM] $\left[\mathrm{MeSO}_{3}\right]$ and $[\mathrm{EMIM}]\left[\mathrm{CF}_{3} \mathrm{SO}_{3}\right]$ are less stable, and the kinetics of decomposition are easy to determine by ambient pressure measurements, but the vapour pressure can only be deduced from $\mathrm{HV}$ experiments. Thus, the combination of ambient pressure TG and of HV measurements is ideal to determine both the vapour pressure and thermal stability of ILs.

Instead of the frequently used onset temperature, the maximum operating temperature of ILs with regard to thermal degradation should be calculated by the kinetic parameters and a suitable criterion of the maximum allowable mass loss with time. Based on the experience obtained up to now, the following strategy is proposed for users of ILs:

1. At first, ambient pressure TG-experiments with two different inert gases should be done. The molar masses of the gases should be as different as possible, as this leads to a large difference of the diffusion coefficients of the vapour (ionic pairs of the IL) in these gases, and consequently to a reliable measurement effect, if evaporation and not (only) thermal degradation takes place. In this work, $\mathrm{N}_{2}$ and $\mathrm{He}$ were used, which leads to a difference in the diffusion coefficients of a factor of about 2.5 .

2. If the rates of mass loss in $\mathrm{N}_{2}$ and $\mathrm{He}$ are equal, only decomposition takes place, and the respective kinetic parameters can be determined by fitting of the TG-experiments as described in this paper (eqn (3), (16) and (17)) with the pre-exponential factor $k_{0}$ and the activation energy $E_{\mathrm{A}}$ as fitting parameters. If possible, experiments with a high heating rate should be conducted to suppress evaporation as far as possible.

3. If the rates of mass loss in $\mathrm{N}_{2}$ and $\mathrm{He}$ are not equal, evaporation plays a role and may even determine the overall mass loss. Then the (ambient pressure) mass loss has to be modelled by considering evaporation and decomposition (eqn (4)). Experiments at different heating rates should be conducted, e.g. at a low heating rate to enhance the contribution of evaporation. A suitable correlation for the mass transfer coefficient for cylindrical crucibles in overflow of a gas is given in a previous publication, ${ }^{12}$ which finally leads to the vapour pressure equation with the entropy term and the enthalpy of vaporization as fitting parameters.

4. If even at the lowest heating rate only decomposition occurs (i.e. no change of TG signal with different gases), the vapour pressure cannot be determined by ambient pressure TGA. Hence, complimentary HV (effusion) experiments, for example by means of a magnetic suspension balance, are needed. 
In this case, eqn (7) is valid to calculate the vapour pressure based on the measured rate of mass loss.

5. If the rate constant of decomposition is known, the maximum operation temperature can be easily calculated: For the relatively strict criterion of a mass loss of $1 \% / \mathrm{a}$, eqn (15) can be used, e.g. for an industrial application of ILs. For a different criterion with regard to the limit of mass loss and decomposition time, the general eqn (22) should be taken, for example, by researchers who only want to measure a certain property of an IL in a certain experimental time of, say, only an hour, but have to be sure that the properties do not change considerably during the measurement.

6. If the vapour pressure (equation) is known, the maximum operation temperature can only be estimated, if the conditions of mass transport are well-known: In closed vessels or open systems without throughput of a gas, evaporation losses are negligible, and only decomposition limits the maximum operation temperature. For "highly volatile" ILs like [EMIM] $\left[\mathrm{NTf}_{2}\right]$ and [BMIM] $\left[\mathrm{NTf}_{2}\right]$, a permanent contact with a gas flowing through or over the IL may lead to considerable mass losses by evaporation. For a given flow rate, the maximum operation temperature can then be calculated by the vapour pressure and a simple mass balance (see case III in section 4.4.2).

\section{Symbols}

\begin{tabular}{|c|c|}
\hline$A_{\mathrm{C}}$ & Liquid surface area, $\mathrm{m}^{2}$ \\
\hline$c_{\text {vap }}$ & Concentration of vapour molecules, $\mathrm{mol} \mathrm{m}^{-3}$ \\
\hline$C_{\text {vap }}$ & Entropy term in vapour pressure equation \\
\hline$d_{\text {bubble }}$ & Diameter of bubble, $\mathrm{m}$ \\
\hline$d_{\mathrm{C}}$ & (Outer) diameter of cylindrical crucible, $\mathrm{m}$ \\
\hline$D_{i, \mathrm{~g}}$ & Diffusion coefficient of $i$ in the gas phase, $\mathrm{g} \mathrm{m}^{2} \mathrm{~s}^{-1}$ \\
\hline$E_{\mathrm{A}}$ & $\begin{array}{l}\text { Activation energy of thermal decomposition, } \\
\mathrm{J} \mathrm{mol}^{-1}\end{array}$ \\
\hline$h_{\mathrm{F}}\left(h_{\mathrm{F}, 0}\right)$ & $\begin{array}{l}\text { Filling level (height) of cylindrical crucible (initial } \\
\left.\text { value of } h_{\mathrm{F}}\right), \mathrm{m}\end{array}$ \\
\hline HR & Heating rate, $\mathrm{K} \mathrm{s}^{-1}$ \\
\hline$k$ & Boltzmann constant, $1.38 \times 10^{-23} \mathrm{~J} \mathrm{~K}^{-1}$ \\
\hline$k_{0}$ & Pre-exponential factor of $k_{\text {decomposition }}, \mathrm{s}^{-1}$ \\
\hline$k_{\text {decomposition }}$ & $\begin{array}{l}\text { Reaction rate constant of thermal decomposition, } \\
\mathrm{s}^{-1}\end{array}$ \\
\hline$M$ & Molar mass, $\mathrm{kg} \mathrm{mol}^{-1}$ \\
\hline$m\left(m_{0}\right)$ & Mass (initial mass), $\mathrm{kg}$ \\
\hline$n$ & Number of moles, mol \\
\hline$p^{0}$ & Standard pressure, $10^{5} \mathrm{~Pa}$ \\
\hline$p_{\text {ref }}$ & Reference pressure, $1 \mathrm{~Pa}$ \\
\hline$p_{\text {total }}$ & Total pressure, $\mathrm{Pa}$ \\
\hline$p_{\text {vap }}$ & Vapour pressure, $\mathrm{Pa}$ \\
\hline$R$ & Gas constant, $8.314 \mathrm{~J} \mathrm{~mol}^{-1} \mathrm{~K}^{-1}$ \\
\hline$R e_{\mathrm{d}}$ & $\begin{array}{l}\text { Reynolds number based on diameter of cylindric } \\
\text { crucible }\left(d_{\mathrm{C}}\right)\end{array}$ \\
\hline$S h_{\mathrm{d}}$ & $\begin{array}{l}\text { Sherwood number (with crucible's diameter as char- } \\
\text { acteristic length) }\end{array}$ \\
\hline$T$ & Temperature, $\mathrm{K},{ }^{\circ} \mathrm{C}$ \\
\hline$T_{\text {boil, } 1 \text { bar }}$ & Normal boiling temperature (boiling at $1 \mathrm{bar}$ ), $\mathrm{K},{ }^{\circ} \mathrm{C}$ \\
\hline$T_{\text {crit }}$ & Critical operation temperature, $\mathrm{K},{ }^{\circ} \mathrm{C}$ \\
\hline$T_{\max , 1 \% / 1 \mathrm{a}}$ & $\begin{array}{l}\text { Operation temperature where } 1 \% \text { mass loss is } \\
\text { reached per year, } \mathrm{K},{ }^{\circ} \mathrm{C}\end{array}$ \\
\hline$T_{\text {onset }}$ & Onset temperature of a TG measurement, $\mathrm{K},{ }^{\circ} \mathrm{C}$ \\
\hline
\end{tabular}

$T_{\text {onset, } 1 \%} \quad$ Temperature where $1 \%$ mass loss occurred in a TG measurement, $\mathrm{K},{ }^{\circ} \mathrm{C}$

$u_{\text {mol }} \quad$ Mean velocity of vapour/gas molecules, $\mathrm{m} \mathrm{s}^{-1}$

$X \quad$ Degree of mass loss by evaporation and/or thermal decomposition

$\Delta_{\text {vap }} H \quad$ Enthalpy of vaporization, $\mathrm{J} \mathrm{mol}^{-1}$

$\Delta_{\text {vap }} S^{0} \quad$ Standard entropy of vaporization (at $p^{0}=1$ bar $=$ $\left.10^{5} \mathrm{~Pa}\right), \mathrm{J} \mathrm{mol}^{-1} \mathrm{~K}^{-1}$

$\Lambda \quad$ Mean free path, $\mathrm{m}$

$\beta_{\mathrm{C}} \quad$ Mass transfer coefficient for cylindrical crucible (overflow of gas), $\mathrm{m} \mathrm{s}^{-1}$

$\delta \quad$ Thickness of boundary layer, $\mathrm{m}$

$\gamma_{\text {onset }} \quad$ Arrhenius number at $T=T_{\text {onset, } 1 \%}$

$\rho \quad$ Density, $\mathrm{kg} \mathrm{m}^{-3}$

$\sigma \quad$ Collision cross-section of molecule, $\mathrm{m}^{2}$

$\sigma_{\mathrm{IL}} \quad$ Surface tension of ionic liquid, $\mathrm{N} \mathrm{m}^{-1}$

\section{Abbreviations}

$[\mathrm{BMIM}]\left[\mathrm{NTf}_{2}\right]$

$[\mathrm{BMIM}]\left[\mathrm{PF}_{6}\right]$

DTG Derivative thermogravimetry

] $\left.\mathrm{CF}_{3} \mathrm{SO}_{3}\right]$ 1-Ethyl-3-methylimidazolium trifluoromethylsulfonate

[EMIM] $\left[\mathrm{MeSO}_{3}\right]$ 1-Ethyl-3-methylimidazolium methylsulfonate

[EMIM][NTf $\left.{ }_{2}\right]$ 1-Ethyl-3-methylimidazolium bis(trifluoromethylsulfonyl)imide

HV High vacuum $\left(0.1 \mathrm{~Pa}<p<10^{-7} \mathrm{~Pa}\right)$

IL(s) Ionic liquid(s)

MSB

$\mathrm{MSB}_{\mathrm{HV}}$

$\mathrm{MSB}_{\text {ap }}$

NTP

$\mathrm{TG}_{\text {ap }}$

TGA

\section{References}

1 K. R. K. R. Seddon, J. Chem. Technol. Biotechnol., 1997, 68, 351-356.

2 R. A. Sheldon, R. M. Lau, M. J. Sorgedrager, F. van Rantwijk and K. R. Seddon, Green Chem., 2002, 4, 147-151.

3 J. Esser, P. Wasserscheid and A. A Jess, Green Chem., 2004, 6, $316-$ 322.

4 L. P. N. Rebelo, J. N. Canongia Lopes, J. M. S. S. Esperanca and E. Filipe, J. Phys. Chem. B, 2005, 109, 6040-6043.

5 M. J. Earle, J. M. S. S. Esperanca, M. A. Gilea, J. N. Canongia Lopes, L. P. N. Rebelo, J. W. Magee, K. R. Seddon and J. A. Widegren, Nature, 2006, 439, 831.

6 Y. U. Paulechka, D. H. Zaitsau, G. J. Kabo and A A. Strechan, Thermochim. Acta, 2005, 439, 158-160.

7 Y. U. Paulechka, G. J. Kabo, A. V. Blokhin, O. A. Vydrov, J. W. Magee and M. Frenkel, J. Chem. Eng. Data, 2003, 48, 457-462.

8 J. D. Holbrey and R. D. Rogers, in ed. P. Wasserscheid and T. Welton, Ionic liquids in synthesis, Wiley-VCH, Weinheim, 2008.

9 A. Fernández, J. S. José, J. García and F. Rodríguez, J. Chem. Eng. Data, 2007, 52, 1979-1983. 
10 U. Domanska and R. Bogel-Likasik, J. Phys. Chem. B, 2005, 109, 12124-12132.

11 H. L. Ngo, K. LeCompte, L. Hargens and A. B. McEwen, Thermochim. Acta, 2000, 357-358, 97-102.

12 F. Heym, B. Etzold, J. Haber and A. Jess, Phys. Chem. Chem. Phys., 2010, 12, 12089-12100.

13 A. Seeberger, A. K. Andresen and A. Jess, Phys. Chem. Chem. Phys., 2009, 11, 9375.

14 D. M. Fox, J. W. Gilman, H. C. De Long and P. C. Trulove, J. Chem. Thermodyn., 2005, 37, 900 .

15 K. J. Baranyai, G. B. Deacon, D. R. MacFarlane, J. M. Pringle and J. L. Scott, Aust. J. Chem., 2004, 57, 145.

16 T. J. Wooster, K. M. Johanson, K. J. Fraser, D. R. MacFarlane and J. L. Scott, Green Chem., 2006, 8, 691.

17 M. D. Nyman, S. B. Desu and C. H. Peng, Chem. Mater., 1993, 5, 1636.

18 J. P. Armstrong, C. Hurst, R. G. Jones, P. Licence, K. R. J. Lovelock, Christopher J. Satterley and I. J. Villar-Garcia, Phys. Chem. Chem. Phys., 2007, 9, 982-990.

19 D. H. Zaitsau, G. J. Kabo, A. A. Strechan, Y. U. Paulechka, A. Tschersich, S. P. Verevkin and A. Heintz, J. Phys. Chem. A, 2006, 110, 7303.

20 E. N. Fuller, P. D. Schettler and J. C. Giddings, Ind. Eng. Chem., 1966, 58, 19.

21 P. W. Atkins and J. J. de Paula, Physical Chemistry, Oxford University Press, Oxford, 2002.

22 A. Deyko, K. R. J. Lovelock, J. A. Corfield, A. W. Taylor, P. N. Gooden, I. J. Villar-Garcia, P. Licence, R. G. Jones, V. G. Krasovskiy,
E. A. Chernikova and L. M. Kustov, Phys. Chem. Chem. Phys., 2009, 11, 8544-8555.

23 J. M. Crosthwaite, M. J. Muldoon, J. K. Dixon, J. L. Anderson and J. F. Brennecke, J. Chem. Thermodyn., 2005, 37, 559.

24 F. Heym, PhD thesis, University Bayreuth, Germany, in preparation. 25 A. Boesmann, P. Wasserscheid, EUCHEM Conference on Molten Salts and Ionic Liquids. 14.-19.03.2010, Bamberg, 14./19.03.2010, 182.

26 T. J. Ford, Ind. Eng. Chem. Fundam., 1986, 25, 240-243.

27 A. W. Scaroni, R. G. Jenkins and P. L. Walker, Carbon, 1991, 29, 969-980.

28 G. I. Senum and J. R. T. Yang, J. Therm. Anal., 1977, 11, 445-447.

29 J. Dykyj and J. Svoboda, Landolt-Börnstein., Vapor pressures of chemicals, vol. 20, Springer, Berlin, 1999.

30 J. D. McKinley and J. E. Vance, J. Chem. Phys., 1954, 22, 1120 1124.

31 U. Kernchen, B. Etzold, W. Korth and A. A. Jess, Chem. Eng. Technol., 2007, 30, 985-994.

32 A. Riisager, P. Wasserscheid, R. v. Hal and R. Fehrmann, J. Catal., 2003, 219, 452.

33 Riisager, K. M. Eriksen, P. Wasserscheid and R. Fehrmann, Catal. Lett., 2003, 90, 149.

34 C. P. Mehnert, R. A. Cook, N. C. Dispenziere and M. Afeworki, J. Am. Chem. Soc., 2002, 124, 12932.

35 F. Heym, J. Haber, W. Korth, B. J. M. Etzold and A. Jess, Chem. Eng. Technol., 2010, 33, 1625-1634.

36 P. J. Carvalho, M. G. Freire, I. M. Marrucho, A. J. Queimada and J. A. P. Coutinho, J. Chem. Eng. Data, 2008, 53, 1346-1350. 